\title{
Representaciones sociales frente a la responsabilidad social de la industria petrolera y su influencia en la calidad de vida de los habitantes de la vereda Rubiales*
}

\section{Social representations with regards to corporate responsibility of the oil industry}

and its influence on the quality of life of the inhabitants of the district of Rubiales

Jennifer Sherelyn Sierra Arevalo**

Recibido: 23 de junio de 2015

Revisado: 6 de julio de 2015

Aprobado: 2 de febrero de 2016

\section{Resumen}

El artículo analiza las representaciones sociales que los habitantes de la vereda Rubiales, municipio de Puerto Gaitán, departamento del Meta, construyen frente a la

* Artículo de investigación presentado para optar al título de Maestría en Estudios y Gestión del Desarrollo de la Facultad de Ciencias Económicas y Sociales de la Universidad de La Salle. Cómo citar este artículo: Sierra, J. S. (2015). Representaciones sociales frente a la responsabilidad social de la industria petrolera y su influencia en la calidad de vida de los habitantes de la vereda Rubiales. Revista CIFE, 17(27), 103-147

** Profesional como Trabajadora Social de la Universidad Colegio Mayor de Cundinamarca, Magíster en Estudio y Gestión de Desarrollo de la Universidad de La Salle. Correo: jsherelyn@hotmail.com 
responsabilidad social de la industria petrolera y la influencia en su calidad de vida. La investigación inicia con un abordaje de los procesos de objetivación y anclaje que se dan durante la construcción de una representación social. Posteriormente, se considera la responsabilidad social empresarial como el compromiso voluntario que las organizaciones asumen de integrar las expectativas y preocupaciones de los diferentes grupos de interés, apuntando hacia un desarrollo sostenible y generando confianza y credibilidad. También se analiza que la calidad de vida es un concepto social que parte de las necesidades y de los intereses de una persona en comunidad, fundamentada en su propia realidad. Finalmente, mediante el análisis de la información recolectada por medio de la observación directa y la aplicación de entrevistas semiestructuradas, se logra determinar que, para los habitantes de la vereda Rubiales, la responsabilidad social empresarial es un canal de comunicación entre la comunidad y las empresas, por medio del cual se canalizan ofertas laborales; es quien les ayuda a resolver sus problemas o necesidades, principalmente de salud, y quienes velan por el bienestar de la comunidad. Adicionalmente, en cuanto a calidad de vida, refieren que el poder acceder a un empleo con un salario superior al que se encuentra afuera les permite satisfacer sus necesidades básicas y acceder a bienes y servicios, lo que les significa un mejoramiento de su calidad de vida.

Palabras clave: Responsabilidad social empresarial, calidad de vida, representaciones sociales.

Clasificación JEL: M14, M12, D64, O15, I18. 


\begin{abstract}
The article analyzes the social representations that the inhabitants of the district of Rubiales, municipality of Puerto Gaitán, department of Meta, build with regards to the social responsibility of the oil industry and the influence on their quality of life. The research begins with an approach of the objectification and anchoring processes that occur during the construction of a social representation. Subsequently, it considers corporate social responsibility as a voluntary commitment that organizations take on to integrate the expectations and concerns of the various stakeholders, aiming towards a sustainable development and building trust and credibility. It also analyzes that the quality of life is a social concept of the needs and interests of a person in community, based on their own reality. Finally, by analyzing the information collected through direct observation and the application of semi-structured interviews, it is determined that, for the inhabitants of the district of Rubiales, corporate social responsibility is a communication channel between the community and the companies, through which job offers are channeled; it is the one who helps them solve their problems or needs, mainly in health, and who watch over the welfare of the community. Additionally, in terms of quality of life, they relate that being able to access a job with a higher salary than the one found outside allows them to meet their basic needs and access to goods and services, which for them means an improvement in their quality of life.
\end{abstract}

Keywords: Corporate social responsibility, quality of life, social representations.

Classification JEL: M14, M12, D64, O15, I18. 


\section{Introducción}

La responsabilidad social empresarial, entendida como el compromiso voluntario que asumen las organizaciones de integrar las expectativas y preocupaciones de los diferentes grupos de interés, apunta hacia un desarrollo sostenible que genera confianza y credibilidad. Las grandes empresas se interesan por tener un desempeño social y ambiental responsable manifestado en la definición de políticas y principios que inciden en la calidad de vida de uno de los grupos de interés más importantes: las comunidades, los habitantes de los sectores que forman parte del área de influencia de la operación de dichas industrias.

Frente al tema se han realizado algunos estudios. Según Barroso (2008), para la mayoría de los participantes, la responsabilidad empresarial (RSE) es mejorar la calidad de vida del personal y la contribución a la sociedad. Sin embargo, sus acciones se orientan principalmente hacia el trato e imagen ante el cliente, con el objetivo de vender más. Son pocos los que se refieren al cuidado y a la preservación del medio ambiente o al tema de la filantropía.

Por su parte, León (2009) analiza las representaciones sociales de un grupo de estudiantes de Contaduría Pública con respecto al concepto "responsabilidad social". Se considera la responsabilidad social como un discurso estratégico; los estudiantes poseen una estructura de sentido común que, como cuerpo de disposiciones, tiene autonomía relativa frente a las formas de circulación hegemónicas del discurso de la responsabilidad social.

Estos y otros estudios dan muestra de los impactos de la industria, tanto en el medio ambiente como en la sociedad. Sin embargo, las investigaciones que se consiguen son evaluaciones cuantitativas y análisis estadísticos sobre variables socioeconómicas, pero no se encuentran estudios de tipo cualitativo que permitan identificar la percepción, los imaginarios, el sentir de los sujetos sociales que conviven e incluso construyen sus vidas junto a estas dinámicas industriales. Por lo tanto, es importante reconocer, entender y analizar las representaciones sociales acerca de la responsabilidad social empresarial de la industria petrolera y su influencia en la calidad de vida de los habitantes de la vereda Rubiales, del municipio de Puerto Gaitán, Meta. Un estudio para el periodo 2002-2012 permite no solo a las compañías de hidrocarburos, sino a todas aquellas industrias que operan en el sector rural, hacer una comparación entre sus políticas de responsabilidad social empresarial y las necesidades o problemáticas de las comunidades, determinando si se está cumpliendo con el objetivo de estas o si, por el contrario, es preciso replantearlas sin perder de vista el principio de no sustitución de Estado. Al respecto, para el Estado, conocer las problemáticas sociales y las necesidades que tienen las comunidades rurales es una oportunidad de trabajar en la formulación de políticas sociales que garanticen su atención haciéndolas parte de la agenda política. 
Para obtener esta información, se realizaron entrevistas en profundidad a 20 de las 70 familias que conforman la vereda Rubiales y se identificaron unidades de análisis, las cuales posteriormente fueron codificadas a fin de presentar los resultados del estudio.

La representación social construida por las familias entrevistadas no dista mucho del concepto de responsabilidad social, pues para ellos significa un canal de comunicación entre la comunidad y las empresas, un medio por el cual se canalizan las ofertas laborales; es quien les ayuda a resolver sus problemas o necesidades, principalmente de salud, así como para presentar inquietudes o inconformidades, y son quienes velan por el bienestar de la comunidad. Lo anterior fue mencionado en el orden de importancia captado en sus relatos. Adicionalmente, refieren que la calidad de vida tanto de quienes están allí desde antes de la llegada de las operadoras como de quienes han llegado a consecuencia de estas ha mejorado significativamente, lo que da un reconocimiento importante al componente económico.

Para el sustento de la presente investigación, se encontrará a continuación el desarrollo de los conceptos de representación social desde diferentes autores, y lo mismo sucede con la categoría de responsabilidad social empresarial y la de calidad de vida. Posteriormente, se hará un recorrido por diferentes investigaciones y trabajos que han abordado las temáticas relacionadas con la investigación. Sigue la metodología que orientó el estudio, la cual fue clave para el logro de los objetivos propuestos, pues permitió un análisis amplio y detallado de la temática planteada y dio lugar a la presentación de los resultados. Finalmente, se concluirá con un análisis y algunas recomendaciones dirigidas a las industrias petroleras.

\section{Marco teórico-conceptual}

Los referentes teóricos que soportan y orientan el presente trabajo de investigación son el desarrollo humano y el desarrollo rural. El primero ubica a la persona en el centro del desarrollo y busca potenciar todas sus fortalezas, habilidades y capacidades con el fin de permitirse el ejercicio de sus libertades, lo que constituye un mejoramiento de la calidad de vida de las personas y de los grupos humanos. El segundo se refiere a las diferentes iniciativas políticas y estrategias, principalmente en los ámbitos social y económico, que se adoptan para generar el mejoramiento de la calidad de vida en zonas no urbanas. En este contexto es importante contemplar la diversidad cultural de los pueblos que allí habitan.

$\mathrm{Al}$ respecto, el PNUD menciona que:

El desarrollo humano es un proceso mediante el cual se amplían las oportunidades de los individuos, las más importantes de las cuales son una vida prolongada y saludable, acceso a la educación y el disfrute de un nivel de vida decente. Otras oportunidades incluyen la libertad política, la garantía de los derechos humanos y el respeto a sí mismo. (PNUD, 1990, p. 33.). 
Que las personas sean quienes tomen las decisiones que impacten en su desarrollo e influyan en el relacionamiento con su entorno permite un crecimiento del ser el cual se refleja en su desempeño como ser social en el interior de una comunidad.

Hace poco el país volvió de nuevo la mirada hacia el mundo rural con unas perspectivas diferentes: como fuente de oportunidades para el crecimiento económico en un planeta globalizado, ávido de alimentos, de materias primas y de recursos ambientales. Ambas perspectivas son confluentes e interdependientes. Los ciudadanos globales han comprendido que la calidad de vida en las urbes depende del bienestar de quienes habitan las zonas rurales. (PNUD, 2011, p. 13.).

El desarrollo rural presenta hoy una amplia gama de posibilidades referidas a actividades económicas que generan importantes aportes a la economía del país; estas actividades pueden llegar a contribuir con el desarrollo de las regiones si los recursos que proveen por medio del pago de impuestos, de las regalías inversiones sociales, entre otras, se utilizan de manera apropiada mediante el desarrollo de proyectos sociales y productivos que beneficien a las comunidades campesinas, lo cual se verá reflejado en la calidad de vida y el desarrollo del país.

Teniendo en cuenta lo anterior, se analizaron, en primer lugar, las representaciones sociales, con el fin de conocer los imaginarios que construyen los habitantes rurales frente a la responsabilidad social de las empresas que operan en la región, esto con el propósito de evaluar si el ejercicio de sus políticas sociales está influyendo en la calidad de vida de los habitantes de la vereda Rubiales.

Las representaciones sociales se refieren a la construcción social de los procesos psicológicos, de la percepción del hombre ante un fenómeno. La representación es, por lo tanto, una modalidad particular de conocimiento cuya función es la elaboración de los comportamientos de los individuos.

Es una mirada al sentido común y a sus construcciones, esto es considerar el saber del sentido común como un tipo de conocimiento que en su dinámica puede estar referido a la idea del mundo que tiene un individuo, pero también a la que tienen los de su clase social, país, género (...) podríamos agregar que el concepto de representación social agrupa el conjunto de imágenes, sistemas de referencia, categorías y teorías que crean diversas formas concretas de vida social. (Moscovici, citado por Salcedo, 1994, p. 158).

Las representaciones sociales están presentes en el hecho de que los individuos organizan sus pensamientos y acciones de una manera particular en la vida diaria, de tal forma que respondan a sus expectativas e intereses personales, y es a partir de la interacción con las demás personas que obtienen la información para construir su discurso frente a las diferentes circunstancias. Se considera social por ser compartida entre muchas personas que presentan una o varias características en común. 
Las representaciones sociales tienen los siguientes procesos sociales: 1) la objetivación, que "es el proceso de transformar información abstracta en conocimiento concreto por medio de la comunicación, que culmina con la creación de significados figurativos, metafóricos o simbólicos compartidos en distintos grados" (Rodríguez, 2008, p.19); 2) el anclaje, proceso de la representación social que designa tanto las formas de inserción en lo social como la función que se deriva de ello y que, en palabras de Jodelet (1985, p. 51), "se refiere al enraizamiento social de la representación y su objeto". Es cuando las personas se apropian de la representación social haciéndola suya y manifestándola en su cotidianidad.

Analizando ahora la responsabilidad social, entendida como "el compromiso voluntario y explícito que las organizaciones asumen frente a las expectativas y acciones concertadas que se generan con las partes interesadas (stakeholders), en materia de desarrollo humano integral, esta [les] permite a las organizaciones asegurar el crecimiento económico, el desarrollo social y el equilibrio ambiental partiendo del cumplimiento de las disposiciones legales (ICONTEC, 2009, p.12)".

La responsabilidad social empresarial es, además del cumplimiento estricto de las obligaciones legales vigentes, la integración voluntaria por parte de la empresa, manifiesta en su gobierno y gestión, en su estrategia, en sus políticas y procedimientos, en las preocupaciones sociales, laborales y ambientales y en el respeto por los derechos humanos que surgen de la relación y el diálogo transparentes con sus grupos de interés, responsabilizándose así de las consecuencias y los impactos que derivan de sus acciones.

La responsabilidad social se relaciona con los diferentes grupos de interés. El objeto de estudio de la presente investigación es la comunidad, razón por la cual el estudio se basa en el análisis de sus políticas de relacionamiento con esta, los programas de inversión social, de contratación de mano de obra local (MOL), la compra de bienes y servicios a nivel local, la atención a la comunidad y el bienestar laboral.

En cuanto a la calidad de vida, la Organización Mundial de la Salud (citado por León, 2009, p. 19) la define como "la percepción que un individuo tiene de su lugar en la existencia, en el contexto de la cultura y del sistema de valores en los que vive y en relación con sus objetivos, sus expectativas, sus normas, sus inquietudes. Se trata de un concepto muy amplio que está influido de modo complejo por la salud física del sujeto, su estado psicológico, su nivel de independencia, sus relaciones sociales, así como su relación con los elementos esenciales de su entorno".

La calidad de vida contempla varias dimensiones del ser humano, como son la salud, la educación, las condiciones habitacionales o de vivienda, la recreación y el ingreso. Se puede decir que, si una persona es saludable, tiene acceso a la educación, un lugar digno donde vivir, un trabajo y espacios de ocio o recreación, tiene entonces una buena calidad 
de vida. Para Vergara, Alonso, Palacio y Rojas (2009, p. 383), "calidad de vida es un concepto social e históricamente determinado que parte de las necesidades e intereses de una persona en comunidad y tiene como meta la realización de un proyecto de vida auténtico, fundamentado en su propia realidad, el cual permite la participación de todos los actores sociales; el ciudadano es el centro y el catalizador de la energía".

El análisis de la implementación de las políticas permitirá determinar si efectivamente las empresas están aportando al mejoramiento de la calidad de vida de los habitantes de la vereda Rubiales y, en consecuencia, si contribuyen al desarrollo de la región.

\section{Revisión de la literatura}

Estudios han analizado el tema de las representaciones sociales, la responsabilidad social y la calidad de vida. Garzón (2010) describe la representación social en lo femenino y lo masculino que construye un grupo de jóvenes adolescentes en el Liceo Contadora, institución educativa mixta de la localidad de Ciudad Bolívar. Es un estudio cualitativo con enfoque fenomenológico que identifica las representaciones sociales y los estereotipos sexistas presentes en las relaciones de género.

Barroso (2008) presenta un estudio de cuarenta empresas de Mérida (Yucatán, México). Su objetivo es verificar qué entienden por RSE sus directivos, si creen que es necesaria para el éxito de sus empresas y si estas son socialmente responsables. Además, determina cuáles son sus acciones de RSE en caso de llevarlas a cabo. Los resultados muestran que, para la mayoría de los participantes, la RSE es mejorar la calidad de vida del personal y la contribución a la sociedad. Sin embargo, sus acciones se orientan principalmente hacia el trato y la imagen ante el cliente, esto con el objetivo de vender más. Pocos se refieren al cuidado y a la preservación del medio ambiente o al tema de la filantropía. En ninguna de las empresas se cumple el concepto completo, por lo que no pueden llamarse socialmente responsables en el sentido amplio y estricto de su significado.

León, Barragán y Ravelo (2009) analizan las representaciones sociales que un grupo de estudiantes de Contaduría Pública tiene del concepto "responsabilidad social". El documento expone una discusión sobre los aspectos concernientes al sentido común y la posibilidad que tienen las representaciones sociales como instrumental metodológico para su análisis. Posteriormente, se considera la responsabilidad social como un discurso estratégico generado en ciertas instancias del poder asociadas con el campo de la empresa internacional y se analizan sus mecanismos de difusión y disposición. Finalmente, mediante el análisis de información capturada por los instrumentos de investigación (encuesta y talleres llaves de asociación), se concluye que los estudiantes poseen una estructura de sentido común que, como cuerpo de disposiciones, tiene autonomía relativa frente a las formas de circulación hegemónicas del discurso de la responsabilidad social. 
Hall (2008) estudia la calidad de vida en vecindarios urbanos de Costa Rica. En su trabajo se sopesa la valoración de comodidades en vecindarios urbanos y la satisfacción tanto con esos vecindarios como con la vida en general. En primer lugar, los alquileres se usan para calcular el precio de las comodidades de vecindarios de San José, lo cual permite explicar $39 \%$ de la variación estandarizada de los alquileres. Algunas zonas se ubican muy arriba en la clasificación de características de la vivienda, pero no tanto en la clasificación de comodidades del vecindario, lo que sugiere que medidas indirectas de políticas pudieran contribuir a reducir la desigualdad en zonas urbanas mediante el mejoramiento de las comodidades de los vecindarios. En segundo lugar, se analizan las diferencias en la valoración de las comodidades calculando los precios en distintas zonas urbanas.

\section{Aproximación metodológica}

Para el presente estudio se realizó una investigación de tipo cualitativo que permitió hacer un análisis descriptivo y explicativo de las dinámicas sociales objeto de estudio, permitiendo hacer una observación directa, holística y no generalizada de la realidad.

El interés del estudio surgió a partir del análisis de la realidad social y cultural manifiesta, no a partir de conceptos previos emitidos desde alguna disciplina. La pregunta de investigación se orientó hacia lo subjetivo, lo cultural, el proceso social y el significado individual y colectivo de las realidades. La observación se efectuó a partir de la presencia en la vereda Rubiales y el diálogo fue un ejercicio permanente en el que los habitantes expresaron su percepción frente a la responsabilidad social. Esta exploración permitió construir un referente teórico que sirviera de guía, pero que no se constituyera en "marco" cerrado para la interpretación y el análisis.

Los actores están constituidos por los habitantes de la vereda Rubiales, que se diferencian en tres grupos: quienes tienen ascendencia indígena, que llevan más de veinte años viviendo en ese lugar; los colonos, "blancos" como se denominan ellos, que son las personas que llevan en la vereda alrededor de diez años y que han estado allí desde antes de que llegaran las operadoras; y la población flotante o foráneos, quienes no superan los tres años en la vereda. En total, en la vereda se cuenta con setenta familias, de las cuales se entrevistaron veinte.

Según Sandoval (1997), al establecer las pautas para la implementación de un proceso de investigación, se deben formular tres preguntas:

1. ¿Qué tan profundo y qué tan extenso debe ser el proceso de recolección de datos? Es necesario precisar que tanto la profundidad sobre la extensión como la explicitud de la calidad sobre la magnitud de la cantidad juegan un papel prioritario para la investigación cualitativa. El límite de la profundización surge del nivel de claridad 
que se va obteniendo a medida que se avanza en el proceso de investigación y de la extensión de la mayor o menor riqueza de información que se derive de las fuentes que han sido exploradas. Se entrevistaron veinte familias, ya que las respuestas se empezaron a tornar repetitivas, sin encontrarse nuevos elementos para registrar diferentes de los enunciados por los demás entrevistados; esto indicó que se contaba con información suficiente para analizar.

2. ¿Por dónde iniciar y dónde terminar el proceso de recolección de datos? Frente al inicio y al cierre del proceso de recolección de información, es necesario contar con una fase exploratoria, que es la puerta de entrada a una etapa de mayor precisión de profundidad. En cuanto al cierre, está determinado idealmente por el logro del límite de comprensión de la realidad objeto de análisis. En este sentido, se realizó la aplicación de una prueba piloto inicial que indicó la pertinencia de las preguntas y la asertividad de estas, lo que permitió hacer algunos ajustes al instrumento de recolección. Adicionalmente, fue necesario conocer el tiempo estimado en cada entrevista y la disposición de los entrevistados.

3. ¿A quién incluir y a quién excluir de la recolección de datos? Esto solo se podrá responder en función de los objetivos y la dinámica generada por la investigación. Solo se incluyeron habitantes de la vereda Rubiales, se contemplaron todos los grupos poblacionales y finalmente se entrevistaron veinte familias que fueron seleccionadas aleatoriamente dependiendo de su disponibilidad de tiempo para atender la entrevista.

En cuanto a la técnica utilizada, se escogió la entrevista en profundidad, la cual se acompañó de un instrumento tipo cuestionario que consta de 14 preguntas que responden a los objetivos de la investigación. Dichas preguntas fueron previamente elaboradas a partir de los acercamientos iniciales y el conocimiento de la realidad. Cabe aclarar que las preguntas no fueron formuladas de manera sistemática, ya que la entrevista se convierte en un diálogo en el cual se van insertando las preguntas a medida que la charla fluye. El instrumento es una guía que permite no dejar pasar por alto alguna de las categorías que se pretenden indagar, pero es casi imperceptible para el entrevistado. Las entrevistas se realizaron de manera proporcional a la representatividad que tiene cada uno de estos grupos en la vereda, por este motivo, se entrevistaron tres familias con ascendencia indígena, siete colonas y diez foráneas.

\section{Análisis de la información}

La técnica de análisis de contenido se utilizó para el procesamiento de la información. Laurence Bardin (citado por Abela, 2002, p. 3) define esta técnica como "el conjunto de técnicas de análisis de las comunicaciones tendentes a obtener indicadores (cuantitativos o no) por procedimientos sistemáticos y objetivos de descripción del contenido de 
los mensajes, permitiendo la inferencia de conocimientos relativos a las condiciones de producción/recepción (contexto social) de estos mensajes". El análisis de contenido fue efectuado por medio de la codificación, la cual consiste en "una transformación mediante reglas precisas de los datos brutos del texto. Esta transformación o descomposición del texto permite su representación en índices numéricos o alfabéticos (Ibíd., p. 14). Para poder realizar esta codificación, fue necesario definir el universo (entrevista transcrita), las unidades de análisis (segmentos de la entrevista) y las categorías de análisis (en las cuales son clasificadas las unidades de análisis).

Una vez codificados los datos, estos fueron transferidos a una matriz con el fin de analizarlos, de esta forma, para la presentación de resultados se elaboraron matrices simples con las que se pretende mostrar las creencias, las vivencias y los valores que las familias de la vereda Rubiales construyen frente a la responsabilidad social empresarial.

Las familias están identificadas por número (F1, F2, F3) y por grupo (AI ascendencia indígena, $\mathrm{C}$ colonos y $\mathrm{F}$ foráneos).

\section{Matriz de análisis}

Categoría I. Datos de identificación

\begin{tabular}{|c|c|c|c|c|c|}
\hline Familia & Integrantes & Edades & $\begin{array}{c}\text { Seguridad } \\
\text { Social }\end{array}$ & $\begin{array}{l}\text { Tiempo de } \\
\text { Permanencia } \\
\text { en la Vereda }\end{array}$ & $\begin{array}{c}\text { Tiene } \\
\text { Propiedad }\end{array}$ \\
\hline $\mathrm{Fl}-\mathrm{AI}$ & 5 & $\begin{array}{c}0-9(2) \\
10-17(1) \\
18-25(1) \\
36-50(1)\end{array}$ & Sí, EPS. & 36 años & Sí \\
\hline $\mathrm{F} 2-\mathrm{AI}$ & 7 & $\begin{array}{c}0-9(4) \\
26-35(2) \\
51-70(1)\end{array}$ & Sí, Sisbén. & 25 años & Sí \\
\hline $\mathrm{F} 3-\mathrm{AI}$ & 4 & $\begin{array}{c}0-9(1) \\
18-25(2) \\
51-70(1)\end{array}$ & Sí, Sisbén. & 19 años & Sí \\
\hline $\mathrm{F} 4-\mathrm{C}$ & 4 & $\begin{array}{l}18-25(2) \\
26-35(1) \\
51-70(1)\end{array}$ & Sí, EPS. & 28 años & Sí \\
\hline $\mathrm{F} 5-\mathrm{C}$ & 7 & $\begin{array}{l}18-25(2) \\
26-35(2) \\
36-50(2) \\
51-70(1)\end{array}$ & Sí, Sisbén. & 12 años & Sí \\
\hline
\end{tabular}




\begin{tabular}{|c|c|c|c|c|c|}
\hline Familia & Integrantes & Edades & $\begin{array}{l}\text { Seguridad } \\
\text { Social }\end{array}$ & $\begin{array}{c}\text { Tiempo de } \\
\text { Permanencia } \\
\text { en la Vereda }\end{array}$ & $\begin{array}{c}\text { Tiene } \\
\text { Propiedad }\end{array}$ \\
\hline $\mathrm{F} 6-\mathrm{C}$ & 7 & $\begin{array}{c}0-9(2) \\
10-17(2) \\
36-50(2) \\
51-70(1)\end{array}$ & $\begin{array}{l}\text { Sí, Colmédica, y } \\
\text { mi papá, Sisbén. }\end{array}$ & 12 años & Sí \\
\hline F7 - C & 5 & $\begin{array}{l}26-35(3) \\
36-50(1) \\
51-70(1)\end{array}$ & Sí, EPS. & 9 años & Sí \\
\hline $\mathrm{F} 8-\mathrm{C}$ & 7 & $\begin{array}{c}0-9(1) \\
10-17(4) \\
36-50(1) \\
51-70(1)\end{array}$ & Sí, EPS. & 9 años & Sí \\
\hline $\mathrm{F} 9-\mathrm{C}$ & 4 & $\begin{array}{l}10-17(1) \\
18-25(1) \\
36-50(2)\end{array}$ & $\begin{array}{c}\text { Todos tenemos, } \\
\text { pero poco la } \\
\text { usamos. }\end{array}$ & 6 años & Sí \\
\hline $\mathrm{F} 10-\mathrm{C}$ & 5 & $\begin{array}{l}10-17(1) \\
18-25(1) \\
26-35(1) \\
36-50(2)\end{array}$ & Sí, Sisbén y EPS. & 5 años & No \\
\hline $\mathrm{F} 11-\mathrm{G}$ & 6 & $\begin{array}{c}0-9(1) \\
10-17(3) \\
26-35(1) \\
36-50(1)\end{array}$ & Sí, Sisbén. & 5 años & Sí \\
\hline $\mathrm{F} 12-\mathrm{F}$ & 5 & $\begin{array}{c}0-9(2) \\
10-17(1) \\
36-50(2)\end{array}$ & Sí, Sisbén. & 4 años & Sí \\
\hline $\mathrm{F} 13-\mathrm{F}$ & 2 & $\begin{array}{l}26-35(1) \\
51-70(1)\end{array}$ & Sí, Sisbén. & 4 años & $\begin{array}{c}\text { No, soy } \\
\text { encargado. }\end{array}$ \\
\hline $\mathrm{F} 14-\mathrm{F}$ & 4 & $\begin{array}{c}0-9(1) \\
18-25(1) \\
36-50(2)\end{array}$ & $\begin{array}{c}\text { Sí, dos Sisbén y } \\
\text { dos EPS. }\end{array}$ & 3 años & Sí \\
\hline $\mathrm{F} 15-\mathrm{F}$ & 4 & $\begin{array}{c}0-9(1) \\
10-17(1) \\
26-35(1) \\
36-50(1)\end{array}$ & Sí, EPS. & 3 años & Sí \\
\hline $\mathrm{F} 16-\mathrm{F}$ & 7 & $\begin{array}{l}18-25(5) \\
36-50(2)\end{array}$ & Sí, EPS. & 2 años & Sí \\
\hline $\mathrm{F} 17-\mathrm{F}$ & 5 & $\begin{array}{l}10-17(1) \\
18-25(2) \\
36-50(2)\end{array}$ & Sí, EPS. & 2 años & Sí $_{1}$ \\
\hline
\end{tabular}


Representaciones sociales frente a la responsabilidad social de la industria petrolera y su influencia en la calidad...

Jennifer Sherelyn Sierra Arevalo

\begin{tabular}{|c|c|c|c|c|c|}
\hline Familia & Integrantes & Edades & $\begin{array}{l}\text { Seguridad } \\
\text { Social }\end{array}$ & $\begin{array}{c}\text { Tiempo de } \\
\text { Permanencia } \\
\text { en la Vereda }\end{array}$ & $\begin{array}{c}\text { Tiene } \\
\text { Propiedad }\end{array}$ \\
\hline F18 - F & 5 & $\begin{array}{c}0-9(1) \\
10-17(1) \\
18-25(1) \\
26-35(1) \\
36-50(1)\end{array}$ & No, nada. & 2 años & Sí \\
\hline $\mathrm{F} 19-\mathrm{F}$ & 10 & $\begin{array}{c}0-9(3) \\
10-17(1) \\
18-25(2) \\
26-35(2) \\
51-70(2)\end{array}$ & Sí, EPS. & 2 años & Sí \\
\hline $\mathrm{F} 20-\mathrm{F}$ & 3 & $\begin{array}{c}0-9(1) \\
26-35(2)\end{array}$ & Sí, EPS. & 3 años & No \\
\hline
\end{tabular}

Fuente: Construcción propia a partir de los datos suministrados

Teniendo en cuenta la distribución de las setenta familias entre los grupos con ascendencia indígena, los colonos y los foráneos, se realizó proporcionalmente la selección de las familias. Se entrevistaron tres del primer grupo, ocho del segundo y nueve del tercero. La clasificación de colonos y foráneos se realizó en razón del lugar de origen y el tiempo de permanencia en la vereda.

El promedio de personas por familia es de cinco, y la distribución de grupos etarios es similar. Se encontraron 20 personas de 0 a 9 años, 17 personas de 10 a 17 años, 20 personas de 18 a 25 años, 17 personas de 26 a 35 años, 22 personas de 36 a 50 años y 10 personas de 51 a 70 años. Esto refleja una homogeneidad en la población, lo cual sugiere el desarrollo de proyectos para todos los grupos etarios: niños, jóvenes, adultos y adultos mayores. Otro dato importante es que, de las veinte familias entrevistadas, diecinueve tienen seguridad social; sin embargo, no la pueden disfrutar, ya que el centro médico más cercano se encuentra a más de 170 km, en el casco urbano de Puerto Gaitán.

\section{Matriz de análisis}

Categoría II. Responsabilidad Social

¿Qué entiende o qué significa para usted la Responsabilidad Social?

\begin{tabular}{l|l|l} 
Familia & \multicolumn{1}{c}{ Objetivación } & Anclaje \\
\hline & *Personas que se reúnen con las comunidades. & \\
\hline F1 - AI & $\begin{array}{l}\text { *Para asuntos laborales } \\
\text { *Informar cuando se va a hacer algún trabajo. }\end{array}$ & *Resolver dificultades.
\end{tabular}




\begin{tabular}{l|l|l} 
Familia & Objetivación & Anclaje \\
\hline F2 - AI &
\end{tabular}

\begin{tabular}{|c|c|c|}
\hline $\mathrm{F} 3-\mathrm{AI}$ & $\begin{array}{l}\text { *Son las muchachas. } \\
\text { *Con las que se consiguen los puestos de } \\
\text { trabajo. }\end{array}$ & $\begin{array}{l}\text { *Ayudan a la comunidad con los } \\
\text { problemas que se presentan. }\end{array}$ \\
\hline $\mathrm{F} 4-\mathrm{C}$ & *Es como un eje. & *Para ayudar a la comunidad. \\
\hline $\mathrm{F} 5-\mathrm{C}$ & $\begin{array}{l}\text { *El contacto del personal de trabajo que van } \\
\text { pidiendo. }\end{array}$ & $\begin{array}{l}\text { *Como un hermano mayor. } \\
\text { *Muchos beneficios, es bueno. }\end{array}$ \\
\hline $\mathrm{F} 6-\mathrm{C}$ & $\begin{array}{l}\text { *Ha sido bueno, cuando he necesitado he } \\
\text { recibido el apoyo. }\end{array}$ & \\
\hline $\mathrm{F} 7-\mathrm{C}$ & *Canal entre la empresa y la comunidad. & $\begin{array}{l}\text { *Encargado de velar por el bienestar de } \\
\text { la comunidad. }\end{array}$ \\
\hline $\mathrm{F} 8-\mathrm{C}$ & & $\begin{array}{l}\text { *Para mí... que algún favor, para qué, } \\
\text { muy bueno. }\end{array}$ \\
\hline $\mathrm{F} 9-\mathrm{C}$ & $\begin{array}{l}\text { *Un área de la empresa que se relaciona con } \\
\text { la comunidad. }\end{array}$ & $\begin{array}{l}\text { *Solucionar los problemas que se } \\
\text { presentan con la comunidad. }\end{array}$ \\
\hline $\mathrm{F} 10-\mathrm{C}$ & $\begin{array}{l}\text { *El intermedio entre la comunidad y las } \\
\text { empresas contratantes. } \\
\text { *Estar pendiente de cualquier inconformidad } \\
\text { de los trabajadores. }\end{array}$ & $\begin{array}{l}\text { *Ha estado de la mano con la comuni- } \\
\text { dad haciendo proyectos. }\end{array}$ \\
\hline $\mathrm{F} 11-\mathrm{F}$ & $\begin{array}{l}\text { *Es como el intermediario entre la empresa y } \\
\text { la comunidad. } \\
\text { *Grupo de personas que trabajan con la } \\
\text { comunidad. }\end{array}$ & *Son los encargados de los proyectos. \\
\hline $\mathrm{F} 12-\mathrm{F}$ & $\begin{array}{l}\text { *Es un ente donde la comunidad dirige quejas } \\
\text { y reclamos acerca de la empresa y en cuanto } \\
\text { a trabajo. }\end{array}$ & *Solicitar colaboración de algo. \\
\hline $\mathrm{F} 13-\mathrm{F}$ & $\begin{array}{l}\text { *Es la que gestiona todas las ayudas que le } \\
\text { dan a uno. }\end{array}$ & \\
\hline $\mathrm{F} 14-\mathrm{F}$ & $\begin{array}{l}\text { *Estar pendiente de las comunidades, de } \\
\text { los enfermos, de las contaminaciones, del } \\
\text { transporte. }\end{array}$ & \\
\hline $\mathrm{F} 15-\mathrm{F}$ & $\begin{array}{l}\text { *Es un puente entre las operadoras y la } \\
\text { comunidad. } \\
\text { *Con ustedes es que uno habla para trabajo y } \\
\text { también para pedir la ambulancia. }\end{array}$ & $\begin{array}{l}\text { *Sí, son como los que le ayudan a } \\
\text { uno con los problemas aquí en la } \\
\text { comunidad. }\end{array}$ \\
\hline
\end{tabular}




\begin{tabular}{|c|c|c|}
\hline Familia & Objetivación & Anclaje \\
\hline $\mathrm{F} 16-\mathrm{F}$ & $\begin{array}{l}\text { *Trabajar de la mano con la comunidad. } \\
\text { *Un intermediario de la comunidad ante la } \\
\text { empresa para que se consigan los beneficios. }\end{array}$ & \\
\hline $\mathrm{F} 17-\mathrm{F}$ & $\begin{array}{l}\text { *Entiendo que es un departamento creado } \\
\text { por todas las empresas que tienen influencia } \\
\text { en algún sector. }\end{array}$ & $\begin{array}{l}\text { *Las empresas se preocupan [por } \\
\text { saber] en qué le pueden ayudar a la } \\
\text { comunidad. } \\
\text { *Para colaborarles en sus necesidades. }\end{array}$ \\
\hline $\mathrm{F} 18-\mathrm{F}$ & $\begin{array}{l}\text { *Es el ente que está pendiente de las cosas de } \\
\text { la comunidad. } \\
\text { *Para mí eso es responsabilidad social, la } \\
\text { orientación de los proyectos, todo eso. }\end{array}$ & $\begin{array}{l}\text { *Está pendiente de las cosas de la } \\
\text { comunidad. }\end{array}$ \\
\hline $\mathrm{F} 19-\mathrm{F}$ & $\begin{array}{l}\text { *Es valorar lo que se tiene o lo que se consi- } \\
\text { gue. }\end{array}$ & \\
\hline $\mathrm{F} 20-\mathrm{F}$ & $\begin{array}{l}\text { *Sé que estaban haciendo proyectos } \\
\text { productivos. }\end{array}$ & $\begin{array}{l}\text { *Yo lo veo como un padrino para la } \\
\text { escuela. }\end{array}$ \\
\hline
\end{tabular}

Fuente: Construcción propia a partir de los datos suministrados

Comparando el concepto de responsabilidad social con las construcciones sociales elaboradas por las familias, se puede ver una objetivación del concepto en relación con que la RSE es el canal de comunicación entre los grupos de interés, como la comunidad, los trabajadores, los contratistas, entre otros, y las empresas, que por medio de esta área gestionan compromisos como la atención a sus necesidades en materia de desarrollo humano, con la que las familias entrevistadas dan relevancia al tema del empleo y mediante la cual se desarrollan los proyectos sociales y productivos. Ahora, desde el anclaje, que es la forma como las familias han hecho propia la significación de la responsabilidad social, la reconocen como una figura que ayuda a resolver todo tipo de necesidades:

"Yo la veo como un padrino para la escuela... es como un hermano mayor".

(F20-F, Comunicación personal del 28 de febrero de 2013). 
ISSN: 0124-3551 / Año 17, No 27 / julio-diciembre / pp. 103-148

\section{Matriz de análisis}

Categoría II. Responsabilidad Social

¿Conoce los proyectos o servicios que ofrece Responsabilidad Social?

\begin{tabular}{|c|c|c|c|c|c|c|}
\hline Familia & Educación & Salud & Vivienda & Transporte & $\begin{array}{l}\text { Proyectos } \\
\text { Educativos }\end{array}$ & Otros \\
\hline $\mathrm{F} 1-\mathrm{AI}$ & * La escuela & $\begin{array}{l}\text { *Ambulancia } \\
\text { *Brigadas }\end{array}$ & $\begin{array}{l}\text { *Mejoramiento } \\
\text { de vivienda }\end{array}$ & *Los buses & $\begin{array}{l}\text { *Proyectos } \\
\text { productivos }\end{array}$ & \\
\hline $\mathrm{F} 2-\mathrm{AI}$ & *Diplomados & *Ambulancia & & *Los buses & $\begin{array}{l}\text { *Granjas } \\
\text { integrales }\end{array}$ & \\
\hline $\mathrm{F} 3-\mathrm{AI}$ & *Diplomados & *Ambulancia & $\begin{array}{l}\text { *Mejoramiento } \\
\text { de vivienda }\end{array}$ & *Los buses & & \\
\hline $\mathrm{F} 4-\mathrm{C}$ & $\begin{array}{l}\text { *La escuela } \\
\text { *El programa } \\
\text { cultural }\end{array}$ & $\begin{array}{l}\text { *Enfermería } \\
\text { *Ambulancia }\end{array}$ & & *Los buses & $\begin{array}{l}\text { *Proyectos } \\
\text { productivos }\end{array}$ & $\begin{array}{l}\text { *El } \\
\text { espumado } \\
\text { *La caseta } \\
\text { comunal }\end{array}$ \\
\hline F5 - C & & & *Los buses & $\begin{array}{l}* \text { Proyectos } \\
\text { productivos }\end{array}$ & $\begin{array}{l}\text { *El espumado } \\
\text { *La caseta } \\
\text { comunal }\end{array}$ & \\
\hline $\mathrm{F} 6-\mathrm{C}$ & $\begin{array}{l}\text { *La escuela } \\
\text { *El programa } \\
\text { cultural }\end{array}$ & *Ambulancia & $\begin{array}{l}\text { *Mejoramiento } \\
\text { de vivienda }\end{array}$ & *Los buses & *La citronela & \\
\hline F7 - C & $\begin{array}{l}\text { *Capacita- } \\
\text { ciones } \\
\text { *Diplomados } \\
\text { *La escuela }\end{array}$ & & & $*$ El bus & $\begin{array}{l}\text { *Granjas } \\
\text { integrales } \\
\text { *Plantas } \\
\text { aromáticas }\end{array}$ & $\begin{array}{l}\text { *Familias y } \\
\text { amaneceres } \\
\text { *Salón } \\
\text { comunal }\end{array}$ \\
\hline $\mathrm{F} 8-\mathrm{C}$ & $\begin{array}{l}\text { *La escuela } \\
\text { *El programa } \\
\text { cultural }\end{array}$ & $\begin{array}{l}\text { *Brigada de } \\
\text { salud visual } \\
\text { *Brigada } \\
\text { odontológica }\end{array}$ & & & & \\
\hline $\mathrm{F} 9-\mathrm{C}$ & $\begin{array}{l}\text { *Diplomado } \\
\text { *Becas }\end{array}$ & *Ambulancia & & *El bus & & $\begin{array}{l}\text { *Salón } \\
\text { comunal }\end{array}$ \\
\hline $\mathrm{F} 10-\mathrm{C}$ & $\begin{array}{l}\text { *Diplomados } \\
\text { *El proyecto } \\
\text { de danzas }\end{array}$ & *Ambulancia & & $\begin{array}{l}* \text { Los cinco } \\
\text { buses }\end{array}$ & $\begin{array}{l}\text { *Ganadería } \\
\text { *Agricultura }\end{array}$ & \\
\hline F11 - F & $\begin{array}{l}\text { *El proyecto } \\
\text { cultural } \\
\text { *Diplomados } \\
\text { *La escuela }\end{array}$ & *Ambulancia & & $\begin{array}{l}\text { *La ruta } \\
\text { escolar } \\
\text { *Los buses }\end{array}$ & $\begin{array}{l}\text { *La citronela } \\
\text { *La huerta }\end{array}$ & $\begin{array}{l}\text { *Salón } \\
\text { comunal }\end{array}$ \\
\hline $\mathrm{F} 12-\mathrm{F}$ & $\begin{array}{l}\text { *La escuela } \\
\text { *Los } \\
\text { profesores de } \\
\text { danzas } \\
\text { *Diplomados }\end{array}$ & $\begin{array}{l}\text { *Ambulancia } \\
\text { *Las brigadas } \\
\text { de salud }\end{array}$ & & *Los buses & *La citronela & $\begin{array}{l}\text { *Salón } \\
\text { comunal }\end{array}$ \\
\hline
\end{tabular}


Representaciones sociales frente a la responsabilidad social de la industria petrolera y su influencia en la calidad...

Jennifer Sherelyn Sierra Arevalo

\begin{tabular}{|c|c|c|c|c|c|c|}
\hline Familia & Educación & Salud & Vivienda & Transporte & $\begin{array}{l}\text { Proyectos } \\
\text { Educativos }\end{array}$ & Otros \\
\hline $\mathrm{F} 13-\mathrm{F}$ & *Las becas & $\begin{array}{l}\text { *Médico } \\
\text { *Campañas }\end{array}$ & & *Transporte & & \\
\hline F14-F & *La escuela & *Ambulancia & & $\begin{array}{l}* \mathrm{El} \\
\text { transporte }\end{array}$ & $\begin{array}{l}\text { *La citronel } \\
\text { *Las } \\
\text { terapeutas } \\
\text { *Las gallinas } \\
\text { *Las vacas }\end{array}$ & \\
\hline $\mathrm{F} 15-\mathrm{F}$ & $\begin{array}{l}\text { *Proyecto } \\
\text { cultural }\end{array}$ & $\begin{array}{l}\text { *Odontología } \\
\text { *Ambulancia }\end{array}$ & & $\begin{array}{l}\text { *La ruta } \\
\text { escolar } \\
\text { *El bus }\end{array}$ & & \\
\hline $\mathrm{F} 16-\mathrm{F}$ & & *Ambulancia & & $\begin{array}{l}\text { *El bus } \\
\text { *La ruta } \\
\text { para los } \\
\text { niños }\end{array}$ & $\begin{array}{l}\text { *Ganadería } \\
\text { *Gallinas }\end{array}$ & $\begin{array}{l}\text { *La planta } \\
\text { eléctrica } \\
\text { *Espumado }\end{array}$ \\
\hline $\mathrm{F} 17-\mathrm{F}$ & $\begin{array}{l}\text { *Diplomados } \\
\text { *La escuela } \\
\text { *Las salas de } \\
\text { meta digital }\end{array}$ & *Ambulancia & & $\begin{array}{l}* \mathrm{El} \\
\text { transporte } \\
\text { de la vereda } \\
\text { *El escolar }\end{array}$ & & *ASOVENRU \\
\hline $\mathrm{F} 18-\mathrm{F}$ & $\begin{array}{l}\text { *Programa } \\
\text { de educación } \\
\text { superior }\end{array}$ & $\begin{array}{l}\text { *Ambulancia } \\
\text { *El centro } \\
\text { médico }\end{array}$ & & *Los buses & $\begin{array}{l}\text { *La citronela } \\
\text { *El proyecto } \\
\text { de ganado }\end{array}$ & $\begin{array}{l}\text { *Una planta } \\
\text { eléctrica }\end{array}$ \\
\hline $\mathrm{F} 19-\mathrm{F}$ & $\begin{array}{l}\text { *Proyecto de } \\
\text { sistemas para } \\
\text { los profesores } \\
\text { *Diplomados } \\
\text { *Becas }\end{array}$ & $\begin{array}{l}\text { *Ambulancia } \\
\text { *El centro } \\
\text { médico }\end{array}$ & $\begin{array}{l}\text { *Vivienda } \\
\text { para la gente } \\
\text { indígena }\end{array}$ & & $\begin{array}{l}\text { *Emprendi- } \\
\text { miento } \\
\text { *Talleres para } \\
\text { las mujeres }\end{array}$ & $\begin{array}{l}\text { *Vacaciones } \\
\text { recreativas }\end{array}$ \\
\hline $\mathrm{F} 20-\mathrm{F}$ & & *Ambulancia & & *Buses & $\begin{array}{l}\text { *Proyectos } \\
\text { productivos }\end{array}$ & $\begin{array}{l}\text { *Salón } \\
\text { comunal }\end{array}$ \\
\hline
\end{tabular}

Fuente: Construcción propia a partir de los datos suministrados

En cuanto al reconocimiento de los diferentes proyectos que se desarrollan y han desarrollado a lo largo de estos diez años, las familias refieren los que están vigentes y los que han sido significativos para ellos. Los relacionados con la educación, la salud, el transporte y los proyectos productivos son los más recordados, lo que es de esperarse si se considera, en primera instancia, que los tres primeros temas tienen relación con la satisfacción de necesidades primarias, y en segundo lugar, las condiciones de la vereda en cuanto a la ausencia de estos servicios por parte del Estado. 


\section{Matriz de análisis}

\section{Categoría II. Responsabilidad Social}

¿Considera que se ha beneficiado de los que ha participado? ¿Cómo?

\begin{tabular}{|c|c|c|c|c|c|c|}
\hline Familia & Educación & Salud & Vivienda & Transporte & $\begin{array}{l}\text { Proyectos } \\
\text { Educativos }\end{array}$ & Otros \\
\hline $\mathrm{F} 1-\mathrm{AI}$ & $\begin{array}{l}\text { La escuela } \\
\text { realmente es un } \\
\text { beneficio para } \\
\text { nuestros hijos. }\end{array}$ & $\begin{array}{l}\text { El servicio de } \\
\text { ambulancia... } \\
\text { Las brigadas nos } \\
\text { han beneficiado } \\
\text { a todos. }\end{array}$ & $\begin{array}{l}\text { El único es el } \\
\text { mejoramiento } \\
\text { de vivienda. }\end{array}$ & $\begin{array}{l}\text { También me ha } \\
\text { beneficiado el } \\
\text { transporte. }\end{array}$ & $\begin{array}{l}\text { Los proyectos } \\
\text { productivos } \\
\text { no han } \\
\text { funcionado. }\end{array}$ & \\
\hline $\mathrm{F} 2-\mathrm{AI}$ & $\begin{array}{l}\text { Yo participé de } \\
\text { los diplomados } \\
\text {... Pues sí } \\
\text { me pareció } \\
\text { chévere... } \\
\text { Aprendí un } \\
\text { poquito más. }\end{array}$ & $\begin{array}{l}\text { De la } \\
\text { ambulancia. }\end{array}$ & & $\begin{array}{l}\text { Me he } \\
\text { beneficiado del } \\
\text { transporte. }\end{array}$ & $\begin{array}{l}\text { Pues hasta } \\
\text { ahora llevamos } \\
\text { un proyecto... } \\
\text { Uno ve el } \\
\text { proyecto muy } \\
\text { quedado, nada } \\
\text { de plata... } \\
\text { Las granjas } \\
\text { integrales } \\
\text { también. }\end{array}$ & \\
\hline $\mathrm{F} 3-\mathrm{AI}$ & $\begin{array}{l}\text { Fui a un diplo- } \\
\text { mado. }\end{array}$ & $\begin{array}{l}\text { Si uno tiene el } \\
\text { niño enfermo, } \\
\text { llama a } \\
\text { Responsabilidad } \\
\text { Social y le } \\
\text { mandan la } \\
\text { ambulancia. }\end{array}$ & $\begin{array}{l}\text { La vivienda } \\
\text { mejoró } \\
\text { mucho, la otra } \\
\text { era de moriche } \\
\text { y teja de zinc, } \\
\text { y esta es de } \\
\text { material. }\end{array}$ & $\begin{array}{l}\text { Para el bus solo } \\
\text { toca planillarse y } \\
\text { no cobran. }\end{array}$ & & \\
\hline $\mathrm{F} 4-\mathrm{C}$ & $\begin{array}{l}\text { La escuela fue } \\
\text { un gran apoyo } \\
\text { porque antes } \\
\text { aquí no había } \\
\text { escuela. }\end{array}$ & $\begin{array}{l}\text { La cuestión de } \\
\text { la enfermería } \\
\text { también ha } \\
\text { servido mucho y } \\
\text { la ambulancia, } \\
\text { una ayuda muy } \\
\text { grande. }\end{array}$ & & $\begin{array}{l}\text { No los he } \\
\text { podido utilizar } \\
\text { porque siempre } \\
\text { está el cupo, } \\
\text { pero sí, los buses } \\
\text { son una gran } \\
\text { ayuda también. }\end{array}$ & $\begin{array}{l}\text { Nos apoyaron } \\
\text { con unos bultos } \\
\text { de alambre y } \\
\text { unas semillas. }\end{array}$ & $\begin{array}{l}\text { El espumado } \\
\text { al frente de } \\
\text { las casas } \\
\text { también fue } \\
\text { un alivio } \\
\text { muy grande. } \\
\text { La caseta } \\
\text { comunal. }\end{array}$ \\
\hline $\mathrm{F} 5-\mathrm{C}$ & $\begin{array}{l}\text { El último } \\
\text { diplomado sí, } \\
\text { muy bueno de } \\
\text { verdad porque } \\
\text { la verdad es } \\
\text { que yo no tenía } \\
\text { idea, yo decía } \\
\text { pero, por dónde } \\
\text { arranco... } \\
\text { para granjas } \\
\text { integrales. }\end{array}$ & $\begin{array}{l}\text { Yo pienso que lo } \\
\text { básico, ¿no? Si } \\
\text { alguna persona se } \\
\text { enfermó o algo, } \\
\text { corre para allá... } \\
\text { La ambulancia } \\
\text { está bien. }\end{array}$ & $\begin{array}{l}\text { Hace como } \\
7 \text { u } 8 \text { años, } \\
\text { cuando lo de } \\
\text { las tejas, die- } \\
\text { ron una planta } \\
\text { solar. }\end{array}$ & & $\begin{array}{l}\text { Hace como } 7,8 \\
\text { años... dieron } \\
9 \text { vacas y un } \\
\text { toro. Vamos } \\
\text { a sembrar y } \\
\text { construir un } \\
\text { galpón... Yo me } \\
\text { estoy poniendo } \\
\text { las pilas porque } \\
\text { Pacific va a salir } \\
\text { de aquí. }\end{array}$ & \\
\hline
\end{tabular}


Representaciones sociales frente a la responsabilidad social de la industria petrolera y su influencia en la calidad...

Jennifer Sherelyn Sierra Arevalo

\begin{tabular}{|c|c|c|c|c|c|c|}
\hline Familia & Educación & Salud & Vivienda & Transporte & $\begin{array}{l}\text { Proyectos } \\
\text { Educativos }\end{array}$ & Otros \\
\hline F6 - C & $\begin{array}{l}\text { Pues, también, } \\
\text { porque gracias } \\
\text { a la empresa } \\
\text { tenemos ese } \\
\text { internado, } \\
\text { porque como } \\
\text { fuera. ¡Ay Dios } \\
\text { mío! ¡Ya no } \\
\text { estaría yo acá! }\end{array}$ & $\begin{array}{l}\text { Cuando he } \\
\text { estado enferma, } \\
\text { he necesitado el } \\
\text { apoyo y me han } \\
\text { colaborado así } \\
\text { de sacarme hasta } \\
\text { Puerto Gaitán, } \\
\text { o sea, para mí } \\
\text { me ha servido y } \\
\text { mucho. }\end{array}$ & $\begin{array}{l}\text { Hay empresas } \\
\text { que me han } \\
\text { colaborado } \\
\text { con materiales, } \\
\text { en cosas que } \\
\text { uno necesita } \\
\text { y le saca } \\
\text { provecho. }\end{array}$ & $\begin{array}{l}\text { Pues eso sería } \\
\text { como ser des- } \\
\text { agradecido de } \\
\text { mi parte porque } \\
\text { que lo lleven y } \\
\text { lo traigan a uno } \\
\text { gratis... Briega } \\
\text { uno un poquito } \\
\text { a ratos para lo } \\
\text { de la anotada. }\end{array}$ & $\begin{array}{l}\text { Bien, vamos a } \\
\text { fabricar unas } \\
\text { cosas, por } \\
\text { ahí tengo el } \\
\text { papel, estamos } \\
\text { haciendo el } \\
\text { jabón líquido } \\
\text { y hacemos de } \\
\text { eso que le echa } \\
\text { uno a la ropa y } \\
\text { queda oliendo } \\
\text { a rico. }\end{array}$ & \\
\hline F7 - C & $\begin{array}{l}\text { Claro que sí, } \\
\text { por crecimiento } \\
\text { personal y } \\
\text { profesional, } \\
\text { porque las } \\
\text { capacitaciones } \\
\text { me ayudaron. }\end{array}$ & $\begin{array}{l}\text { He obtenido } \\
\text { beneficio } \\
\text { económico, } \\
\text { el ahorro en } \\
\text { medicamentos y } \\
\text { chequeo médico. }\end{array}$ & & $\begin{array}{l}\text { Ahorro de pagar } \\
\text { un pasaje. }\end{array}$ & $\begin{array}{l}\text { De las plantas } \\
\text { aromáticas } \\
\text { y aceites } \\
\text { esenciales. }\end{array}$ & \\
\hline $\mathrm{F} 8-\mathrm{C}$ & $\begin{array}{l}\text { Esa escuela es } \\
\text { un proyecto de } \\
\text { la empresa... de } \\
\text { Responsabilidad } \\
\text { Social. }\end{array}$ & $\begin{array}{l}\text { Yo también } \\
\text { fui beneficiada } \\
\text { por las gafas... } \\
\text { Estuvo muy } \\
\text { buena también } \\
\text { la de la parte de } \\
\text { odontología. }\end{array}$ & & & & $\begin{array}{l}\text { Esas plantas } \\
\text { solares nos } \\
\text { las dio la } \\
\text { sísmica. }\end{array}$ \\
\hline F9-C & $\begin{array}{l}\text { De las becas, } \\
\text { aunque aquí son } \\
\text { muy peleadas. }\end{array}$ & $\begin{array}{l}\text { La ambulancia, } \\
\text { pero a mí casi no } \\
\text { me gusta llamar } \\
\text { a molestar... Lo } \\
\text { que más me gustó } \\
\text { fue esa brigada, } \\
\text { porque el doctor, } \\
\text { sin hacerme } \\
\text { exámenes, me dijo } \\
\text { de todo lo que yo } \\
\text { sufría... eso fue } \\
\text { buenísimo. }\end{array}$ & & $\begin{array}{l}\text { Sí, claro, } \\
\text { porque aquí no } \\
\text { tenemos bus } \\
\text { de línea y eso } \\
\text { ayuda mucho, } \\
\text { agradecemos } \\
\text { porque es gratis. }\end{array}$ & & $\begin{array}{l}\text { También nos } \\
\text { beneficiamos } \\
\text { del salón } \\
\text { comunal. }\end{array}$ \\
\hline $\mathrm{F} 10-\mathrm{C}$ & $\begin{array}{l}\text { Más que todo } \\
\text { de los estudios, } \\
\text { por mi familia; } \\
\text { para mí } \\
\text { personalmente, } \\
\text { que he tenido } \\
\text { un buen } \\
\text { conocimiento y } \\
\text { enriquecimiento } \\
\text { con mucha } \\
\text { enseñanza por } \\
\text { esos diplomados. }\end{array}$ & La ambulancia & & $\begin{array}{l}\text { Lo del bus, } \\
\text { excelente, diario } \\
\text { que es lo que } \\
\text { tiene uno... } \\
\text { para toda la } \\
\text { comunidad. }\end{array}$ & & \\
\hline
\end{tabular}




\begin{tabular}{|c|c|c|c|c|c|c|}
\hline Familia & Educación & Salud & Vivienda & Transporte & $\begin{array}{l}\text { Proyectos } \\
\text { Educativos }\end{array}$ & Otros \\
\hline F11 - F & $\begin{array}{l}\text { Pues lo de los } \\
\text { diplomados, } \\
\text { de eso sí } \\
\text { participamos } \\
\text { nosotros, eso sí } \\
\text { me pareció muy } \\
\text { bueno. }\end{array}$ & $\begin{array}{l}\text { Prestan un } \\
\text { servicio bueno, } \\
\text { pero no la ambu- } \\
\text { lancia... O sea, } \\
\text { yo pienso que no } \\
\text { se ha presentado } \\
\text { un buen proyecto, } \\
\text { porque debería } \\
\text { haber un puesto } \\
\text { de salud. }\end{array}$ & & $\begin{array}{l}\text { Pues, la verdad, } \\
\text { desde que yo } \\
\text { entré siempre } \\
\text { ha habido bus... } \\
\text { Lo de la ruta } \\
\text { escolar, también. }\end{array}$ & $\begin{array}{l}\text { El de la } \\
\text { citronela... pero } \\
\text { ahorita la verdad } \\
\text { está como uno } \\
\text { desocupado. }\end{array}$ & \\
\hline $\mathrm{F} 12-\mathrm{F}$ & $\begin{array}{l}\text { En el cultural, } \\
\text { mi hijita sí... } \\
\text { bien, bien, le fue } \\
\text { bien, ella tiene } \\
\text { actitud para esas } \\
\text { cosas. }\end{array}$ & $\begin{array}{l}\text { Yo llevé a } \\
\text { mis hijos a } \\
\text { la brigada... } \\
\text { vacunación, } \\
\text { exámenes de los } \\
\text { ojos... a la de } \\
\text { los oídos... las } \\
\text { odontológicas } \\
\text { también. La } \\
\text { ambulancia, yo sí } \\
\text { la he utilizado... } \\
\text { más que todo } \\
\text { con los niños } \\
\text { pequeños... Ahí } \\
\text { viene a la casa de } \\
\text { uno. }\end{array}$ & & $\begin{array}{l}\text { El bus de la } \\
\text { comunidad, } \\
\text { claro el bus sí lo } \\
\text { utilicé... El de la } \\
\text { escuela, el de los } \\
\text { niños también, } \\
\text { claro, ahí se } \\
\text { van mis hijos y } \\
\text { llegan. }\end{array}$ & $\begin{array}{l}\text { Solo tengo el de } \\
\text { citronela. }\end{array}$ & $\begin{array}{l}\text { Desde que } \\
\text { nosotros } \\
\text { hemos } \\
\text { estado } \\
\text { por acá, } \\
\text { él siempre } \\
\text { ha estado } \\
\text { empleado } \\
\text { allá en la } \\
\text { empresa. }\end{array}$ \\
\hline $\mathrm{F} 13-\mathrm{F}$ & & $\begin{array}{l}\text { Médico, ahí está } \\
\text { al día, que cuando } \\
\text { hay campaña, } \\
\text { también. }\end{array}$ & & $\begin{array}{l}\text { El bus de la } \\
\text { comunidad, } \\
\text { claro el bus sí lo } \\
\text { utilicé... El de la } \\
\text { escuela, el de los } \\
\text { niños también, } \\
\text { claro, ahí se } \\
\text { van mis hijos y } \\
\text { llegan. }\end{array}$ & $\begin{array}{l}\text { Solo tengo el de } \\
\text { citronela. }\end{array}$ & $\begin{array}{l}\text { Desde que } \\
\text { nosotros } \\
\text { hemos estado } \\
\text { por acá, } \\
\text { él siempre } \\
\text { ha estado } \\
\text { empleado } \\
\text { allá en la } \\
\text { empresa. }\end{array}$ \\
\hline $\mathrm{F} 14-\mathrm{F}$ & $\begin{array}{l}\text { Sí, la escuela, } \\
\text { pero está muy } \\
\text { descuidada, ahí } \\
\text { sí la veo mal. } \\
\text { Las becas son } \\
\text { otra cosa... Pero } \\
\text { a la gente hay } \\
\text { que rogarle para } \\
\text { que se acerquen } \\
\text { a recibir una } \\
\text { beca. }\end{array}$ & $\begin{array}{l}\text { Sí, claro, la } \\
\text { ambulancia sí, uy } \\
\text { mucho... O sea, } \\
\text { para mí aquí eso } \\
\text { ha sido una de las } \\
\text { mejores... O sea, } \\
\text { han estado muy } \\
\text { pendientes de mí } \\
\text {... No sé los demás } \\
\text { como se sienten, } \\
\text { para mí, sí. }\end{array}$ & & $\begin{array}{l}\text { Me beneficio del } \\
\text { bus, es de lo que } \\
\text { yo más me he } \\
\text { beneficiado. }\end{array}$ & & \\
\hline $\mathrm{F} 15-\mathrm{F}$ & $\begin{array}{l}\text { Sí, al niño le } \\
\text { gusta mucho } \\
\text { eso, ahora } \\
\text { quiere tocar } \\
\text { arpa también. }\end{array}$ & $\begin{array}{l}\text { Lo de } \\
\text { odontología... } \\
\text { Por acá dónde } \\
\text { va a encontrar } \\
\text { odontólogo, } \\
\text { además, eso es } \\
\text { caro. }\end{array}$ & & $\begin{array}{l}\text { La ruta escolar y } \\
\text { el bus de Gaitán. }\end{array}$ & & \\
\hline
\end{tabular}


Representaciones sociales frente a la responsabilidad social de la industria petrolera y su influencia en la calidad...

Jennifer Sherelyn Sierra Arevalo

\begin{tabular}{|c|c|c|c|c|c|c|}
\hline Familia & Educación & Salud & Vivienda & Transporte & $\begin{array}{l}\text { Proyectos } \\
\text { Educativos }\end{array}$ & Otros \\
\hline F16-F & & $\begin{array}{l}\text { Yo me he servido } \\
\text { de la ambulancia, } \\
\text { para mí ha sido } \\
\text { un servicio bueno. }\end{array}$ & & $\begin{array}{l}\text { Yo me he } \\
\text { servido de la } \\
\text { ambulancia, } \\
\text { para mí ha } \\
\text { sido un servicio } \\
\text { bueno. }\end{array}$ & & $\begin{array}{l}\text { Ahorita y } \\
\text { que afortu- } \\
\text { nadamente } \\
\text { las cosas se } \\
\text { nos dieron } \\
\text { fue esa plan- } \\
\text { ta... El otro } \\
\text { proyecto fue } \\
\text { el espumado. }\end{array}$ \\
\hline
\end{tabular}

\begin{tabular}{|c|c|c|c|c|c|c|}
\hline $\mathrm{F} 17-\mathrm{F}$ & $\begin{array}{l}\text { Diplomados... } \\
\text { Mi hijo estudia } \\
\text { en la escuela... } \\
\text { Las nuevas salas } \\
\text { de Meta-digital. }\end{array}$ & La ambulancia. & & $\begin{array}{l}\text { El transporte } \\
\text { de la vereda } \\
\text { a Gaitán ida } \\
\text { y vuelta... El } \\
\text { escolar. }\end{array}$ & & $\begin{array}{l}\text { ASOVENRU, } \\
\text { porque fue } \\
\text { con recursos } \\
\text { de Respon- } \\
\text { sabilidad } \\
\text { Social. }\end{array}$ \\
\hline $\mathrm{F} 18-\mathrm{F}$ & $\begin{array}{l}\text { Sí, incluso mi } \\
\text { hijastro, él } \\
\text { participó... } \\
\text { Incluso como } \\
\text { que estuvo ya en } \\
\text { sorteo. }\end{array}$ & $\begin{array}{l}\text { Una } \\
\text { ambulancia... En } \\
\text { el centro médico, } \\
\text { sí, yo he ido } \\
\text { con mi esposa y } \\
\text { también nos han } \\
\text { atendido. }\end{array}$ & $\begin{array}{l}\text { Eso sí no, } \\
\text { nosotros lo } \\
\text { que hemos } \\
\text { construido... } \\
\text { Nos lo ha dado } \\
\text { el negocio. }\end{array}$ & $\begin{array}{l}\text { Los buses del } \\
\text { transporte. }\end{array}$ & & $\begin{array}{l}\text { Sí, una } \\
\text { planta que } \\
\text { nos dieron } \\
\text { para la } \\
\text { comunidad } \\
\text { porque } \\
\text { estamos sin } \\
\text { agua. }\end{array}$ \\
\hline $\mathrm{F} 19-\mathrm{F}$ & $\begin{array}{l}\text { Los diplomados, } \\
\text { muchas personas } \\
\text { que han querido } \\
\text { han perdido la } \\
\text { oportunidad de } \\
\text { estudiar por la } \\
\text { envidia. }\end{array}$ & $\begin{array}{l}\text { A mí me gusta } \\
\text { porque, digamos, } \\
\text { una urgencia y a } \\
\text { uno lo atienden } \\
\text { acá o me he } \\
\text { acercado al } \\
\text { centro médico de } \\
\text { Arrayanes. }\end{array}$ & & $\begin{array}{l}\text { Del servicio de } \\
\text { transporte. }\end{array}$ & $\begin{array}{l}\text { Emprendi- } \\
\text { miento }\end{array}$ & $\begin{array}{l}\text { Talleres de } \\
\text { valores } \\
\text { hacia la } \\
\text { mujer... fue } \\
\text { un espacio } \\
\text { bueno. Las } \\
\text { vacaciones } \\
\text { recreativas } \\
\text { también fue } \\
\text { un programa } \\
\text { buenísimo. }\end{array}$ \\
\hline $\mathrm{F} 20-\mathrm{F}$ & $\begin{array}{l}\text { Las salidas peda- } \\
\text { gógicas, esa fue } \\
\text { una experiencia } \\
\text { muy bonita. } \\
\text { El programa } \\
\text { en cuanto a la } \\
\text { cultura llanera, } \\
\text { nos sentimos } \\
\text { muy contentos } \\
\text { porque mire, en } \\
\text { eso vimos como } \\
\text { unadisciplina } \\
\text { para los chicos } \\
\text { que estaban } \\
\text { como descuida- } \\
\text { dos en cuanto } \\
\text { al rendimiento } \\
\text { académico. }\end{array}$ & $\begin{array}{l}\text { La ambulancia es } \\
\text { un gran apoyo, } \\
\text { hemos tenido unas } \\
\text { emergencias muy } \\
\text { tenaces. }\end{array}$ & & $\begin{array}{l}\text { Lo de los buses } \\
\text { son servicios } \\
\text { muy buenos } \\
\text { porque aquí } \\
\text { estamos lejos de } \\
\text { la civilización. }\end{array}$ & $\begin{array}{l}\text { Aprendimos } \\
\text { cómo hacer } \\
\text { una destilación, } \\
\text { a separar el } \\
\text { hidrolato del } \\
\text { aceite... Por } \\
\text { allá aprendimos } \\
\text { lo que fue la } \\
\text { elaboración de } \\
\text { los productos de } \\
\text { aseo. }\end{array}$ & \\
\hline
\end{tabular}

Fuente: Construcción propia a partir de los datos suministrados 
Esta matriz muestra cómo los diferentes proyectos han incidido en la vida de los habitantes de Rubiales y qué es lo realmente valioso y necesario para ellos. El reconocimiento que le dan a los proyectos de educación -como la construcción de la escuela, los diplomados y el proyecto cultural llanero-, así como a los servicios de salud, la ambulancia, las brigadas y el centro médico de la operadora, además del transporte, indican el acertado direccionamiento y enfoque de los proyectos y la importancia de construir en conjunto comunidad-empresas.

\section{Matriz de análisis}

\section{Categoría II. Responsabilidad Social}

¿Considera que las empresas que actual y anteriormente han operado en la vereda han sido responsables socialmente?

\begin{tabular}{|c|c|c|}
\hline Familia & Objetivación & Anclaje \\
\hline $\mathrm{F} 1-\mathrm{AI}$ & $\begin{array}{l}\text { No, porque uno como campesino ha tenido } \\
\text { muchos problemas porque la empresa no } \\
\text { pide permiso para entrar a las fincas... } \\
\text { no cumplen con el cuidado del medio } \\
\text { ambiente. }\end{array}$ & \\
\hline $\mathrm{F} 2-\mathrm{AI}$ & ...pero vuelvo y toco el tema del tierrero. & $\begin{array}{l}\text { Sí, han sido un apoyo... en muchas formas } \\
\text { ha sido apoyo... ha sido mejor todo. }\end{array}$ \\
\hline $\mathrm{F} 3-\mathrm{AI}$ & $\begin{array}{l}\text { Pues, sí, porque nos han ayudado mucho y } \\
\text { nos dan cosas que necesitamos, aunque a } \\
\text { veces contaminan el agua. }\end{array}$ & \\
\hline $\mathrm{F} 4-\mathrm{C}$ & & $\begin{array}{l}\text { La verdad es que la empresa para mí sí } \\
\text { ha sido de gran ayuda, la verdad me ha } \\
\text { colaborado bastante y yo me formé con } \\
\text { ellos... Gracias a Dios y a Pacific, que me } \\
\text { han brindado ayuda. }\end{array}$ \\
\hline $\mathrm{F} 5-\mathrm{C}$ & & $\begin{array}{l}\text { Es bueno...puede decir uno en } \\
\text { determinadas circunstancias, sí, cuento con } \\
\text { ellos. }\end{array}$ \\
\hline $\mathrm{F} 6-\mathrm{C}$ & & $\begin{array}{l}\text { Cuando he necesitado, he tenido el apoyo, } \\
\text { pues a mí me parece bueno. }\end{array}$ \\
\hline $\mathrm{F} 7-\mathrm{C}$ & $\begin{array}{l}\text { Pues según mi concepto de Responsabilidad } \\
\text { Social, sí; lo que pasa es que nosotros como } \\
\text { comunidad no hemos sido organizados, se } \\
\text { han presentado algunas falencias, pero los } \\
\text { más culpables hemos sido la comunidad. }\end{array}$ & \\
\hline
\end{tabular}


Representaciones sociales frente a la responsabilidad social de la industria petrolera y su influencia en la calidad...

\begin{tabular}{|c|c|c|}
\hline Familia & Objetivación & Anclaje \\
\hline $\mathrm{F} 8-\mathrm{C}$ & & Pues para mí ha sido buena. \\
\hline $\mathrm{F} 9-\mathrm{C}$ & $\begin{array}{l}\text { Lo que pasa es que los contratistas sí se } \\
\text { portan mal por no cumplir los estándares } \\
\text { de velocidad. }\end{array}$ & $\begin{array}{l}\text { Sí, pues le falta mucho, pero, para qué, la } \\
\text { empresa está muy pendiente de nosotros y } \\
\text { cuando uno pide un favor, se lo hacen. }\end{array}$ \\
\hline $\mathrm{F} 10-\mathrm{C}$ & $\begin{array}{l}\text { Responsabilidad Social ha estado como } \\
\text { de la mano con la comunidad haciendo } \\
\text { proyectos. }\end{array}$ & \\
\hline $\mathrm{F} 11-\mathrm{F}$ & $\begin{array}{l}\text { Por lo menos de la velocidad, que abusan } \\
\text { algunos conductores que es que no } \\
\text { respetan. }\end{array}$ & \\
\hline
\end{tabular}

$\mathrm{F} 12-\mathrm{F}$

\begin{tabular}{|l|l|l|}
\hline \multirow{2}{*}{ F13-F } & $\begin{array}{l}\text { Para mí, creo que es una empresa muy } \\
\text { responsable en su modo de tratar al } \\
\text { personal, a la comunidad, todo porque } \\
\text { están atentos a todo lo que pase y saben } \\
\text { tratar, lo que pasa es que por aquí no } \\
\text { entienden y todo lo quieren es a los } \\
\text { coñazos. }\end{array}$ & $\begin{array}{l}\text { Yo lo que veo es lo que van haciendo, lo } \\
\text { que van dejando, eso es bueno. }\end{array}$ \\
\hline \multirow{2}{*}{ F14-F } & $\begin{array}{l}\text { A veces nos echan contaminación, entonces } \\
\text { no aguanta... } \\
\text { Responsabilidad de los conductores que } \\
\text { votan eso acá. }\end{array}$ \\
\hline F15 - F & $\begin{array}{l}\text { *Yo creo que, pues ustedes, andan } \\
\text { pendientes de la gente y hacen las reuniones } \\
\text { para informar... Bueno, ese asuntico del } \\
\text { polvo es que en verano es un tierrero y el } \\
\text { carrotanque solo pasa dos veces al día. }\end{array}$ \\
\hline
\end{tabular}

F16 - F

$\mathrm{F} 17-\mathrm{F}$

Considero que sí porque uno no puede desconocer.

Por mi parte y de mi familia, mis hijos están muy agradecidos, mis hijos están

F18-F estudiando, el otro trabajando... La señora está muy contenta porque ya tiene una propiedad.

F19-F

He tenido buen respaldo.

F20 - F

Ha estado muy pendiente de la escuela, muy pendiente de lo que necesitamos.

Fuente: Construcción propia a partir de los datos suministrados 
Desde la objetivación del concepto, los habitantes manifiestan que las empresas les han brindado apoyo y ayuda, pero que sí hay un trabajo por hacer en relación con el manejo de material particulado, lo cual les afecta:

"Ese asuntico del polvo es que en verano es un tierrero y el carrotanque solo pasa dos veces al día".

(F15-F, comunicación personal del 26 de febrero de 2013).

Ahora, desde el anclaje del concepto se consideran respaldados y apoyados por las operadoras:

"Sí, han sido un apoyo... en muchas formas ha sido apoyo... ha sido mejor todo"

(F2-AI, comunicación personal del 25 de febrero de 2013).

Sienten que han tenido oportunidades gracias a la presencia de las operadoras:

"Por mi parte y de mi familia, mis hijos están muy agradecidos, mis hijos están estudiando, el otro trabajando... La señora está muy contenta porque ya tiene una propiedad".

(F18-F, comunicación personal del 27de febrero de 2013).

\section{Matriz de análisis}

\section{Categoría II. Responsabilidad Social}

¿Qué cree usted que les hace falta a las operadoras para hacer las cosas mejor?

\begin{tabular}{l|l} 
Familia & \multicolumn{1}{c}{ Expectativas } \\
F1 - AI & $\begin{array}{l}\text { De pronto otro apoyo que uno necesita es el del agua... El apoyo de la luz... ¿.Saben qué } \\
\text { deberían mejorar un poco? Que haya bachiller para los adultos. }\end{array}$ \\
\hline F3 - AI & $\begin{array}{l}\text { No, pues así está bien, de pronto lo del polvo en las vías que le hace mucho daño a los } \\
\text { niños. }\end{array}$ \\
\hline F4 - C & $\begin{array}{l}\text { No, pues en cuestión de salud, a mí me parece excelente... En la cuestión del bus, uno no } \\
\text { les puede exigir más a ustedes, no doctora, bien, todo bien. }\end{array}$ \\
\hline F5 - C & $\begin{array}{l}\text { Pues nada... no, para mí es igual por lo que siempre dicen que venimos a ayudarlo... y las } \\
\text { personas se ilusionan, pero yo nunca he creído en esos cuentos. }\end{array}$ \\
\hline F6 - C & $\begin{array}{l}\text { Es que por eso es que a mí casi no me gusta ir a las reuniones, porque es que la gente } \\
\text { acá son muy montañeros, a mí no me gusta cómo a veces se dirige la comunidad hacia } \\
\text { ustedes. }\end{array}$ \\
\hline
\end{tabular}


Representaciones sociales frente a la responsabilidad social de la industria petrolera y su influencia en la calidad...

Jennifer Sherelyn Sierra Arevalo

\begin{abstract}
Familia
Expectativas

De pronto me esté contradiciendo porque sé a quién le corresponde cada cosa, pero lo que le hace falta a Responsabilidad Social es que comprometa al Estado... a darnos los F7 - C servicios públicos

La empresa no le da migajas al gobierno, los grandes jefes deberían gestionar la energía, si lo logran, reinarán por siempre.

F8 - C No sé si es parte de allá de la Junta, pero hay mucha gente de la comunidad sin trabajo y hay mucha gente que uno mira que es de afuera y uno mira con trabajo.

F9 - C Que acaben con ese problema del polvo, si solucionan eso, nos tendrían contentos a todos.

F10-C ejemplo, tres becas, entonces nosotros mismos vamos a nivelar las familias que quieren y que necesitan.
\end{abstract}

Por lo menos lo de la velocidad, que abusan algunos conductores que es que no respetan.

F11 - F En lo de esta cuestión del agua... De un puesto de salud se beneficiaría toda la comunidad, y un buen acueducto, que se beneficiaran no unos, sino todos.

Tener más comunicación... mejores relaciones con las juntas, para que ayuden a apoyar proyectos para la comunidad... Pues que por acá llegue la energía, que por acá haya servicios públicos... que cuando la empresa de aquí a mañana se vaya, quede algo, montar una microempresa o cosas así.

$\mathrm{F} 13-\mathrm{F}$

Tener más colaboración con el Estado, con la gobernación, con la alcaldía y colaborarnos a nosotros en lo que es agua, luz y alcantarillado.

$\mathrm{F} 14-\mathrm{F}$

Un curso para aprender a manejar computadores, eso es un proyecto que a mí me gustaría mucho porque es algo que le va a servir a uno mucho más adelante.

F15 - F Falta mucho, sé que no le corresponde a la empresa privada, pero pueden intervenir en servicios públicos, vías, energía y agua.

Aquí lo que nos falta es organizarnos, trabajar organizados... Aquí la gente le deja el trabajo como a los directivos... Yo pienso que lo que hace falta es que haya buena organización, buenos acuerdos

Coger un grupo de emprendedores y dinamizarlos, apoyarlos, llevarlos al extremo, pero F17 - F que muestren que quieren beneficios para la región.

Identificar los líderes y enfocar las energías si queremos que la comunidad progrese.

$\mathrm{F} 18-\mathrm{F}$

Pues no sé hasta qué punto sea Responsabilidad Social el tema del jardín, es que tiene que

$\mathrm{F} 19-\mathrm{F}$ ir de la mano con Bienestar Familiar... Sí, sería buenísimo ese proyecto, eso mejoraría la calidad de vida como la calidad de la educación, porque acá la mayoría de los niños no tienen la trayectoria en un jardín.

$\mathrm{F} 20-\mathrm{F}$

Fuente: Construcción propia a partir de los datos suministrados 
En esta categoría, la principal preocupación de la comunidad es poder contar con los servicios básicos de agua y energía. Para ellos es claro que la empresa privada no puede atender de manera directa estas carencias, pero consideran que las empresas pueden intervenir ante el Estado para que este les atienda sus necesidades primarias, las cuales son su responsabilidad. Se menciona nuevamente el inconveniente con el material particulado.

"Que acaben con ese problema del polvo, si solucionan eso, nos tendrían contentos a todos".

(F9-C, comunicación personal del 26 de febrero de 2013).

\section{Matriz de análisis}

Categoría III. Calidad de vida

¿Considera que las operadoras han influido en poder acceder a servicios públicos o privados?

\begin{tabular}{|c|c|c|}
\hline Familia & Servicios Públicos & Servicios Privados \\
\hline $\mathrm{F} 1-\mathrm{AI}$ & Los paneles solares que dio la empresa. & $\begin{array}{l}\text { El transporte también, empezamos en una } \\
\text { turbo o mulas, ahora tenemos una buseta. }\end{array}$ \\
\hline $\mathrm{F} 2-\mathrm{AI}$ & & $\begin{array}{l}\text { El transporte, la ambulancia y de proyectos... } \\
\text { Pues, las granjas integrales también. }\end{array}$ \\
\hline $\mathrm{F} 3-\mathrm{AI}$ & $\begin{array}{l}\text { Lo que nos dio un contratista fueron los } \\
\text { paneles solares que han sido muy bue- } \\
\text { nos... La escuela. }\end{array}$ & $\begin{array}{l}\text { Lo de las becas, la ambulancia... Con el } \\
\text { bus... es más fácil salir a comprar. }\end{array}$ \\
\hline $\mathrm{F} 4-\mathrm{C}$ & & $\begin{array}{l}\text { Los buses... y también mucha ayuda con la } \\
\text { enfermería... y la ambulancia. }\end{array}$ \\
\hline $\mathrm{F} 5-\mathrm{C}$ & & La ambulancia y el último diplomado. \\
\hline $\mathrm{F} 6-\mathrm{C}$ & $\begin{array}{l}\text { O sea, que haya mejorado, sí... pues } \\
\text { de todas maneras tenemos la planta de } \\
\text { energía solar. }\end{array}$ & Ahora tenemos servicio de teléfono. \\
\hline
\end{tabular}

Obvio que sí, eso es una realidad, tenemos

F7 - C que reconocer que si la operadora no estuviera, no tendríamos esos beneficios en salud, transporte, telefonía celular.
F8 - C Sí, nos trajeron el agua... la escuela.
No, porque llevamos tiempo pidiéndoles
F9 - $\mathrm{C}$ que nos colaboren con la luz y no han querido.

También la salud... odontología.

El transporte y la salud, sí, la empresa lo ha dado. 
Representaciones sociales frente a la responsabilidad social de la industria petrolera y su influencia en la calidad...

\begin{tabular}{|c|c|c|}
\hline Familia & Servicios Públicos & Servicios Privados \\
\hline $\mathrm{F} 10-\mathrm{C}$ & & $\begin{array}{l}\text { Dos diplomados... Los cinco buses y la } \\
\text { ambulancia. }\end{array}$ \\
\hline $\mathrm{F} 11-\mathrm{F}$ & La escuela. & $\begin{array}{l}\text { Los diplomados... La ambulancia... La ruta } \\
\text { escolar... Los buses. }\end{array}$ \\
\hline $\mathrm{F} 12-\mathrm{F}$ & La escuela. & $\begin{array}{l}\text { Los buses, el bus de la escuela... La } \\
\text { ambulancia... Brigada de salud }\end{array}$ \\
\hline $\mathrm{F} 13-\mathrm{F}$ & $\begin{array}{l}\text { Yo no me suplo de esa agua, pero me } \\
\text { gustó lo de la planta, porque es una } \\
\text { ayuda que le están haciendo al caserío. }\end{array}$ & La ambulancia... El bus. \\
\hline $\mathrm{F} 14-\mathrm{F}$ & La escuela. & La ambulancia... El bus. \\
\hline $\mathrm{F} 15-\mathrm{F}$ & $\begin{array}{l}\text { Pues en estos días entregaron una planta } \\
\text { para el agua... por aquí no hay más } \\
\text { escuelas, solo la que hizo la empresa. }\end{array}$ & $\begin{array}{l}\text { Arrayanes, que lo atiende a uno cuando hay } \\
\text { accidentes, y el servicio de transporte. }\end{array}$ \\
\hline
\end{tabular}

F16-F

$\mathrm{F} 17-\mathrm{F}$

$\mathrm{F} 18-\mathrm{F}$

F19-F De educación.

$\mathrm{F} 20-\mathrm{F}$
Ahora hay comunicación... si no estuviera la empresa, no tendríamos telefonía celular.
Ofrecieron unas becas y la comunidad las distribuyó a su acomodo.

Fomento cultural por medio de los grupos de danza... El apoyo con las ambulancias... El transporte escolar y el de la comunidad.
Bueno, red telefónica, sí.

Lo de salud.

Nos colaboran en la escuela con el agua, la luz, el Internet, el mantenimiento de los equipos.

Fuente: Construcción propia a partir de los datos suministrados

A pesar de la inconformidad que tienen los habitantes de la vereda Rubiales por la ausencia de servicios públicos, reconocen los apoyos tanto de las operadoras como de las empresas contratistas, que han desarrollado proyectos que contribuyen a la satisfacción de necesidades tan importantes como son el agua y la energía; esto se ha hecho mediante la donación de paneles solares y una planta de energía. El contar con una escuela es algo que también valoran significativamente, ya que antes los niños debían trasladarse a Puerto Gaitán o al resguardo Unuma para recibir educación, y un grupo importante de niños simplemente no iba a la escuela. En relación con los servicios privados, como la atención en salud, el transporte y la telefonía celular principalmente, señalan que son posibles por la presencia de las operadoras. 


\title{
Matriz de análisis
}

\author{
Categoría III. Calidad de vida
}

¿Cómo era el acceso a servicios de salud antes de la llegada de las operadoras?

\begin{tabular}{|c|c|c|}
\hline Familia & Experiencias antes & Experiencias últimos diez años \\
\hline $\mathrm{F} 1-\mathrm{AI}$ & $\begin{array}{l}\text { No había ambulancia, le tocaba a uno } \\
\text { tomar cualquier hierbita porque no } \\
\text { había a dónde ir. }\end{array}$ & $\begin{array}{l}\text { Ya cuando llegó Tuscany y luego Coplex, } \\
\text { ellos lo atendían en el centro de salud. }\end{array}$ \\
\hline $\mathrm{F} 2-\mathrm{AI}$ & & Me he beneficiado de la ambulancia. \\
\hline $\mathrm{F} 3-\mathrm{AI}$ & $\begin{array}{l}\text { Con los médicos tradicionales que le } \\
\text { hacían a uno los remedios. Ya cuando } \\
\text { la persona estaba muy enferma, tocaba } \\
\text { salir a Gaitán. }\end{array}$ & $\begin{array}{l}\text { La ambulancia es buena, porque si uno tiene } \\
\text { el niño enfermo, llama a Responsabilidad } \\
\text { Social y le mandan la ambulancia. }\end{array}$ \\
\hline $\mathrm{F} 4-\mathrm{C}$ & & $\begin{array}{l}\text { Acá también me han atendido enfermeras } \\
\text { y muy queridas también, me llevaron, me } \\
\text { trajeron. Para qué, en cuestión de servicios, } \\
\text { muy bueno. }\end{array}$ \\
\hline $\mathrm{F} 5-\mathrm{C}$ & & $\begin{array}{l}\text { Llamé a Responsabilidad Social y me } \\
\text { remitieron con el médico... Yo lo } \\
\text { llevé para allá y lo recibió una doctora en } \\
\text { Arrayanes. }\end{array}$ \\
\hline $\mathrm{F} 6-\mathrm{C}$ & & $\begin{array}{l}\text { Juan Carlos se enfermó y ellos me lo } \\
\text { trasladaron hasta Puerto Gaitán, hasta que el } \\
\text { niño no quedó allá en manos de los médicos } \\
\text { no se descartaron de él, entonces para mí es } \\
\text { bueno. }\end{array}$ \\
\hline
\end{tabular}

No conocí porque cuando llegué, la operadora ya estaba, pero sé que era F7 - C con chamanes, remedios caseros y salir a pie para recurrir al servicio médico de Gaitán.

\begin{tabular}{|l|l}
\hline F8 - C & \\
\hline F9-G & $\begin{array}{l}\text { Antes tocaba a punta de hierbas, tocaba } \\
\text { ir donde el médico tradicional o salir } \\
\text { varajando. Gaitán, pero eso duraba unos días }\end{array}$ \\
\hline
\end{tabular}

Pues para mí ha sido muy buena, pues porque para algunas personas es malo, pero para mí personalmente es bueno porque de esa manera he recibido un apoyo de ustedes cuando he tenido a mi niño enfermo. 
Representaciones sociales frente a la responsabilidad social de la industria petrolera y su influencia en la calidad...

\begin{tabular}{|c|c|c|}
\hline Familia & Experiencias antes & Experiencias últimos diez años \\
\hline $\mathrm{F} 10-\mathrm{C}$ & & $\begin{array}{l}\text { La ambulancia que está directamente para la } \\
\text { comunidad que le presta el servicio en donde } \\
\text { sea, aquí urbano o si tiene que trasladarse a } \\
\text { Puerto Gaitán, también le presta el servicio. }\end{array}$ \\
\hline $\mathrm{F} 11-\mathrm{F}$ & & $\begin{array}{l}\text { ¿La ambulancia? Ah, sí, obvio, prestan un } \\
\text { servicio bueno. }\end{array}$ \\
\hline $\mathrm{F} 12-\mathrm{F}$ & & $\begin{array}{l}\text { He llevado a mis hijos cuando hay brigada } \\
\text { médica... La ambulancia. }\end{array}$ \\
\hline $\mathrm{F} 13-\mathrm{F}$ & & $\begin{array}{l}\text { No, pues voy aquí donde ustedes y me dan } \\
\text { la ambulancia, me mandan la droga, la } \\
\text { inyección y ya, y si hay que mandarme para } \\
\text { Gaitán, bueno, ahí sí me toca meterme la } \\
\text { mano en el bolsillo. }\end{array}$ \\
\hline $\mathrm{F} 14-\mathrm{F}$ & & $\begin{array}{l}\text { La salud en cuanto a ambulancia, porque } \\
\text { usted sabe que puesto de salud }\end{array}$ \\
\hline $\mathrm{F} 15-\mathrm{F}$ & $\begin{array}{l}\text { Donde vivíamos teníamos Sisbén... } \\
\text { Sé que no había nada, por ahí con las } \\
\text { plantas o para Gaitán. }\end{array}$ & \\
\hline
\end{tabular}

F16-F

$\mathrm{F} 17-\mathrm{F}$

Yo me imagino que era malo, porque esto tenía que ser una desolación bárbara.
Yo me he servido de la ambulancia, para mí ha sido un servicio bueno.

La ambulancia.

Yo he ido y me han atendido en el centro médico.

En ocasiones uno pide el servicio y se dirige hasta la casa.

La ambulancia es un gran apoyo... de verdad, es una mano más de apoyo.

Fuente: Construcción propia a partir de los datos suministrados

Anteriormente eran utilizados los métodos tradicionales, y en casos de urgencias viajaban hasta Puerto Gaitán a pie o en bicicleta, lo que significaba un riesgo latente para la vida de los habitantes de la vereda Rubiales. Hoy cuentan con el servicio de ambulancia dispuesto exclusivamente para la atención de la comunidad, el cual acude a la finca del paciente y, en caso de ser necesario, lo traslada al casco urbano o le dan tratamniento en el centro médico de la operadora. La comunidad se siente protegida.

"La ambulancia es buena, porque si uno tiene el niño enfermo, llama a Responsabilidad Social y le mandan la ambulancia".

(F3-AI, comunicación personal del 28 de febrero de 2013). 
Consideran que, en este sentido, sus vidas han mejorado.

\section{Matriz de análisis}

Categoría III. Calidad de vida

¿Cómo era el acceso a servicios de educación antes de la llegada de las operadoras?

\begin{tabular}{|c|c|c|}
\hline Familia & Experiencias antes & Experiencias últimos diez años \\
\hline $\mathrm{F} 1-\mathrm{AI}$ & $\begin{array}{l}\text { Mandaban a los niños a la escuela } \\
\text { del resguardo Unuma, a tres horas en } \\
\text { bicicleta, los dejaban allá los ocho días. }\end{array}$ & $\begin{array}{l}\text { Ahora es muy bueno porque tienen la escuela } \\
\text { cerca y el bus los recoge al frente de la casa. }\end{array}$ \\
\hline $\mathrm{F} 2-\mathrm{AI}$ & & $\begin{array}{l}\text { Yo participé de los diplomados, aprendí un } \\
\text { poquito más. }\end{array}$ \\
\hline $\mathrm{F} 3-\mathrm{AI}$ & $\begin{array}{l}\text { A nosotros nos tocaba cruzar el río para } \\
\text { ir a la escuela del resguardo porque no } \\
\text { estaba la escuela que hizo Pacific. }\end{array}$ & \\
\hline \multicolumn{3}{|l|}{$\mathrm{F} 4-\mathrm{C}$} \\
\hline $\mathrm{F} 5-\mathrm{C}$ & $\begin{array}{l}\text { Aquí se inició esa escuela, aquí en } \\
\text { esta finca... había como once o doce } \\
\text { chicos... y de ahí se hizo la escuela. }\end{array}$ & $\begin{array}{l}\text { Ha progresado mucho... al principio era solo } \\
\text { primaria... y ahora tienen hasta noveno... } \\
\text { entonces sí ha avanzado. }\end{array}$ \\
\hline $\mathrm{F} 6-\mathrm{C}$ & & $\begin{array}{l}\text { Gracias a la empresa tenemos ese internado, } \\
\text { porque cómo fuera. ¡Ay, Dios mío! ¡Ya no } \\
\text { estaría yo acá! }\end{array}$ \\
\hline $\mathrm{F} 7-\mathrm{C}$ & $\begin{array}{l}\text { No había, de pronto había, pero al otro } \\
\text { lado del río para los indígenas. Los } \\
\text { colonos estaban totalmente analfabetas. }\end{array}$ & \\
\hline $\mathrm{F} 8-\mathrm{C}$ & & Esa escuela es un proyecto de la empresa. \\
\hline $\mathrm{F} 9-\mathrm{C}$ & $\begin{array}{l}\text { Le tocaba a uno sacar los hijos a Gaitán } \\
\text { y dejarlos allá. }\end{array}$ & \\
\hline $\mathrm{F} 10-\mathrm{C}$ & & $\begin{array}{l}\text { Nos dictaron los diplomados... Igual, } \\
\text { también he estado en la escuela con el } \\
\text { proyecto de danzas. }\end{array}$ \\
\hline $\mathrm{F} 11-\mathrm{F}$ & & $\begin{array}{l}\text { Tantos comentarios negativos que hay, que } \\
\text { eso no servía... No, cómo así, sí yo he tenido } \\
\text { ahí a mis hijos... Eso es bueno. }\end{array}$ \\
\hline $\mathrm{F} 12-\mathrm{F}$ & & La escuela... Lo de danzas también. \\
\hline
\end{tabular}

$\mathrm{F} 13-\mathrm{F}$ 
Representaciones sociales frente a la responsabilidad social de la industria petrolera y su influencia en la calidad...

Jennifer Sherelyn Sierra Arevalo

\begin{tabular}{|c|c|c|}
\hline $\mathrm{F} 14-\mathrm{F}$ & & $\begin{array}{l}\text { La escuela... Le van a poner mano porque se } \\
\text { va a caer. }\end{array}$ \\
\hline Familia & Experiencias antes & Experiencias últimos diez años \\
\hline $\mathrm{F} 15-\mathrm{F}$ & $\begin{array}{l}\text { Mandaban a los niños a estudiar a } \\
\text { Gaitán porque no había la escuela... } \\
\text { Muchos niños no estudiaban, al mío, } \\
\text { gracias a Dios, sí lo llevaba a la escuela, } \\
\text { pero no tenía ruta. }\end{array}$ & La escuela la hizo Pacific. \\
\hline \multicolumn{3}{|l|}{$\mathrm{F} 16-\mathrm{F}$} \\
\hline $\mathrm{F} 17-\mathrm{F}$ & $\begin{array}{l}\text { Eso prácticamente no, me imagino que } \\
\text { sería un desastre... Era un sitio marginal } \\
\text { donde hay riquezas, pero no se podía } \\
\text { ingresar. }\end{array}$ & $\begin{array}{l}\text { Porque la escuela se hizo con apoyo de las } \\
\text { operadoras. }\end{array}$ \\
\hline $\mathrm{F} 18-\mathrm{F}$ & & $\begin{array}{l}\text { Esas no son oportunidades que se dan todas } \\
\text { las veces que le dan la beca gratis y no le } \\
\text { cuesta nada. }\end{array}$ \\
\hline $\mathrm{F} 19-\mathrm{F}$ & & $\begin{array}{l}\text { De educación se manejó un proyecto con los } \\
\text { profesores... Emprendimiento, los } \\
\text { diplomados. }\end{array}$ \\
\hline $\mathrm{F} 20-\mathrm{F}$ & & $\begin{array}{l}\text { El programa de cultura llanera... Una } \\
\text { disciplina más para los chicos. }\end{array}$ \\
\hline
\end{tabular}

Fuente: Construcción propia a partir de los datos suministrados

En cuanto a educación, anteriormente los niños de familias con ascendencia indígena eran llevados al resguardo más cercano, que queda pasando el río, aproximadamente a tres horas en bicicleta. Los niños eran dejados allí durante la semana. Por su parte, los colonos eran llevados a Puerto Gaitán de manera permanente, y un grupo significativo no estudiaba. Ahora todos tienen la posibilidad de ir a la escuela, que incluso cuenta con una ruta que los recoge en sus fincas. Al programa cultural le dan gran importancia, pues aprovechan el tiempo libre.

"Ahora es muy bueno porque tienen la escuela cerca y el bus los recoge al frente de la casa".

"En cuanto a la cultura llanera, nos sentimos muy contentos porque mire, en eso vimos como una disciplina para los chicos que estaban como descuidados en cuanto al rendimiento académico... y el uso del tiempo libre".

(F1-AI, comunicación personal del 25 de febrero de 2013). 


\section{Matriz de análisis}

Categoría III. Calidad de vida

¿Cómo era el acceso a vivienda antes de la llegada de las operadoras?

\begin{tabular}{|c|c|c|}
\hline Familia & Experiencias antes & Experiencias últimos diez años \\
\hline $\mathrm{F} 1-\mathrm{AI}$ & Las casitas eran de moriche. & $\begin{array}{l}\text { Ahora, con el proyecto que nos tiene Pacific, tenemos } \\
\text { viviendas más dignas y de material. }\end{array}$ \\
\hline \multicolumn{3}{|l|}{$\mathrm{F} 2-\mathrm{AI}$} \\
\hline $\mathrm{F} 3-\mathrm{AI}$ & No había. & Solo hasta ahora que la empresa nos dio estas casas. \\
\hline $\mathrm{F} 4-\mathrm{C}$ & & $\begin{array}{l}\text { La verdad, sí, ahorita hemos visto que les dan su casita y } \\
\text { muy bonita. }\end{array}$ \\
\hline $\mathrm{F} 5-\mathrm{C}$ & & $\begin{array}{l}\text { Escuché que el programa era con los parientes y por ahí vi } \\
\text { unas casas queestán construyendo. }\end{array}$ \\
\hline $\mathrm{F} 6-\mathrm{C}$ & & $\begin{array}{l}\text { Hay empresas que me han colaborado con materiales, en } \\
\text { cosas que unonecesita y les saca provecho, eso sería ser } \\
\text { uno desagradecido. }\end{array}$ \\
\hline $\mathrm{F} 7-\mathrm{C}$ & $\begin{array}{l}\text { Antes las viviendas eran de } \\
\text { tabla y moriche. }\end{array}$ & $\begin{array}{l}\text { ODL colaboró con tejas, motobombas y plantas de ener- } \\
\text { gía.El proyecto de mejoramiento hasta ahora empezó con } \\
\text { la familia Useche. }\end{array}$ \\
\hline $\mathrm{F} 8-\mathrm{C}$ & & $\begin{array}{l}\text { Gracias a Dios tengo aquí mi casa y llevé mucho del bulto } \\
\text { cuando no tenía. }\end{array}$ \\
\hline $\mathrm{F} 9-\mathrm{C}$ & & $\begin{array}{l}\text { Pues eso casi no se ha visto... A mí me regalaron una } \\
\text { maderita para hacer micasa, pero mejoramiento de } \\
\text { vivienda, no. }\end{array}$ \\
\hline \multicolumn{3}{|l|}{$\mathrm{F} 10-\mathrm{C}$} \\
\hline \multicolumn{3}{|l|}{$\mathrm{F} 11-\mathrm{F}$} \\
\hline $\mathrm{F} 12-\mathrm{F}$ & & \\
\hline
\end{tabular}

F13-F

$\mathrm{F} 14-\mathrm{F}$

$\mathrm{F} 15-\mathrm{F}$

Pues de eso sí no se ha hecho nada, porque ni la madera del incinerador.

$\mathrm{F} 16-\mathrm{F}$

$\mathrm{F} 17-\mathrm{F}$

Hasta ahora quienes se han beneficiado son los indígenas, los otros no. Las donaciones de madera han servido para hacer viviendas temporales, con eso laboro, ahorro y luego puedo hacer algo más bonito y a mejor gusto. 
Representaciones sociales frente a la responsabilidad social de la industria petrolera y su influencia en la calidad...

\begin{tabular}{|c|c|c|}
\hline Familia & Experiencias antes & Experiencias últimos diez años \\
\hline $\mathrm{F} 18-\mathrm{F}$ & & Yo he ido y me han atendido en el centro médico. \\
\hline $\mathrm{F} 19-\mathrm{F}$ & & En ocasiones uno pide el servicio y se dirige hasta la casa. \\
\hline $\mathrm{F} 20-\mathrm{F}$ & & $\begin{array}{l}\text { La ambulancia es un gran apoyo... de verdad, es una } \\
\text { mano más de apoyo. }\end{array}$ \\
\hline
\end{tabular}

Fuente: Construcción propia a partir de los datos suministrados

En la vereda Rubiales, la comunidad no ha recibido ningún tipo de apoyo en este sentido por parte del Estado. La operadora actual inició un proyecto del cual se beneficiarán, inicialmente, las doce familias más vulnerables de la vereda. Algunos habitantes manifiestan que han podido mejorar sus condiciones habitacionales gracias al empleo que tienen.

"Las donaciones de madera han servido para hacer viviendas temporales, con eso laboro, ahorro y luego puedo hacer algo más bonito y a mejor gusto".

(F17-F, comunicación personal del 26 de febrero de 2013).

\section{Matriz de análisis}

Categoría III. Calidad de vida

¿Considera que los bienes o el acceso a ellos han estado influenciados por las operadoras?

\begin{tabular}{|c|c|c|}
\hline Familia & Experiencias antes & Experiencias últimos diez años \\
\hline $\mathrm{F} 1-\mathrm{AI}$ & $\begin{array}{l}\text { Antes no había transporte, } \\
\text { tocaba prestarnos las cosas } \\
\text { con las demás chocitas... } \\
\text { Cambiaban marranos por } \\
\text { remesa. }\end{array}$ & $\begin{array}{l}\text { Ahora uno coge cualquier carro de la empresa... Ahora } \\
\text { es más viable todo. }\end{array}$ \\
\hline \multicolumn{3}{|l|}{$\mathrm{F} 2-\mathrm{AI}$} \\
\hline $\mathrm{F} 3-\mathrm{AI}$ & & $\begin{array}{l}\text { Pues sí, porque hay mejor trabajo y se gana más platica } \\
\text { para salir a comprar... También por el bus uno puede } \\
\text { salir día por medio. }\end{array}$ \\
\hline \multicolumn{3}{|l|}{$\mathrm{F} 4-\mathrm{C}$} \\
\hline $\mathrm{F} 5-\mathrm{C}$ & & $\begin{array}{l}\text { Al hijo de don Germán le dió dengue... Mamá venía en } \\
\text { esos días y trajo la ampolla que necesitaba, lo inyectamos } \\
\text { y eso le sirvió. }\end{array}$ \\
\hline
\end{tabular}




\begin{tabular}{|c|c|c|}
\hline Familia & Experiencias antes & Experiencias últimos diez años \\
\hline $\mathrm{F} 6-\mathrm{C}$ & $\begin{array}{l}\text { Cuando nosotros llegamos } \\
\text { acá, escasamente teníamos el } \\
\text { día y la noche. }\end{array}$ & Y ya gracias a Dios tenemos dónde vivir. \\
\hline $\mathrm{F} 7-\mathrm{C}$ & & $\begin{array}{l}\text { He tenido personal hospedado y por el servicio de } \\
\text { alimentación, eso ha hecho que yo pueda mejorar mi es- } \\
\text { tablecimiento y no solamente yo, otras señoras también, } \\
\text { con eso hemos podido surgir. }\end{array}$ \\
\hline $\mathrm{F} 8-\mathrm{C}$ & & $\begin{array}{l}\text { Gracias a Dios tengo aquí mi casa y llevé mucho del } \\
\text { bulto cuando no tenía mi casa, mantenía en cabinas, } \\
\text { de interna trabajé dos años y medio... Ya no trabajo, } \\
\text { mantengo aquí pendiente. }\end{array}$ \\
\hline $\mathrm{F} 9-\mathrm{C}$ & & $\begin{array}{l}\text { De cierta forma sí, porque mi marido trabaja con un } \\
\text { contratista de la empresa y pues el sueldito es bueno y } \\
\text { pues ahora estamos mejor que antes. }\end{array}$ \\
\hline $\mathrm{F} 10-\mathrm{C}$ & & $\begin{array}{l}\text { Importante también el estudio de mis hijos afuera, } \\
\text { porque se han querido superar, de lo mismo que } \\
\text { estoy trabajando me estoy beneficiando yo y mis hijos } \\
\text { también. }\end{array}$ \\
\hline $\mathrm{F} 11-\mathrm{F}$ & & $\begin{array}{l}\text { Ese bus estaba para uno traer las cosas, salíamos, hacía- } \\
\text { mos mercadito, la remesa. }\end{array}$ \\
\hline \multicolumn{3}{|l|}{$\mathrm{F} 12-\mathrm{F}$} \\
\hline $\mathrm{F} 13-\mathrm{F}$ & & $\begin{array}{l}\text { Ahorita me van a traer un medio de transporte que } \\
\text { no tenía... Coloqué un trabajador ahí... Me van a } \\
\text { recompensar con una moto. }\end{array}$ \\
\hline \multicolumn{3}{|l|}{$\mathrm{F} 14-\mathrm{F}$} \\
\hline $\mathrm{F} 15-\mathrm{F}$ & & $\begin{array}{l}\text { Sí, claro, porque teniendo el trabajito uno puede } \\
\text { comprar sus cositas, lo que va necesitando, ahí he ido } \\
\text { levantando mi ranchito. }\end{array}$ \\
\hline \multicolumn{3}{|l|}{ F16-F } \\
\hline $\mathrm{F} 17-\mathrm{F}$ & & $\begin{array}{l}\text { Prácticamente sí en un momento, porque tenemos un } \\
\text { beneficio porque hay trabajo, hay personal circulando, } \\
\text { hay trabajo. }\end{array}$ \\
\hline $\mathrm{F} 18-\mathrm{F}$ & & $\begin{array}{l}\text { El sustento es ese, que los trabajadores compren, que } \\
\text { una comida, que cualquier cosa, entonces ahí se sostiene } \\
\text { uno. }\end{array}$ \\
\hline $\mathrm{F} 19-\mathrm{F}$ & & \\
\hline $\mathrm{F} 20-\mathrm{F}$ & & \\
\hline
\end{tabular}

Fuente: Construcción propia a partir de los datos suministrados 
Las familias refieren que el hecho de tener acceso a un trabajo les ha permitido comprar lo que necesitan, mejorar sus casas y surgir. Mencionan también la importancia del transporte, ya que lo consideran como una facilidad para poder ingresar los mercados y las remesas.

"Pues sí, porque hay mejor trabajo y se gana más platica para salir a comprar... También por el bus uno puede salir día por medio".

(F3-AI, comunicación personal del 28 de febrero de 2013).

\section{Matriz de análisis}

\section{Categoría III. Calidad de vida}

¿Cómo era el acceso a ofertas laborales antes de la llegada de las operadoras?

\begin{tabular}{|c|c|c|}
\hline Familia & Experiencias antes & Experiencias últimos diez años \\
\hline $\mathrm{F} 1-\mathrm{AI}$ & $\begin{array}{l}\text { Trabajábamos como mensual } \\
\text { en fincas... Si en la finca se } \\
\text { enfermaba, del sueldo tenía que } \\
\text { comprar la droga. }\end{array}$ & $\begin{array}{l}\text { Para mí ahora es más viable porque se gana más } \\
\text { plata... } \\
\text { En cambio, con la empresa se encarga de sacarlo y } \\
\text { pagar, y eso es bueno. }\end{array}$ \\
\hline $\mathrm{F} 2-\mathrm{AI}$ & & Sí ha mejorado porque hay trabajo. \\
\hline $\mathrm{F} 3-\mathrm{AI}$ & $\begin{array}{l}\text { Por ahí en las fincas haciendo el } \\
\text { jornal, pero eso pagaban poquito. }\end{array}$ & \\
\hline $\mathrm{F} 4-\mathrm{C}$ & & $\begin{array}{l}\text { Gracias a Dios ustedes me han dado empleo y he } \\
\text { hecho lo que tengo. } \\
\text { ¿Usted ofrece servicio de alojamiento y } \\
\text { alimentación? Sí, para mí eso es ponerme a } \\
\text { trabajar. }\end{array}$ \\
\hline
\end{tabular}

\section{F5 - C}

$\mathrm{F} 6-\mathrm{C}$

No había trabajo, la gente vivía de la yuca, la caza, la pesca y de

F7 - C algunas artesanías... Cuando llegaron las operadoras fue cuando el personal empezó a beneficiarse.
Si no estuvieran las empresas sería complicado porque el personal del barrio

Porvenir, todo ese personal ahí sin trabajo, de qué iban a vivir.

Finalmente todos están trabajando, incluso los muchachos que mi mamá me dijo, ellos también están trabajando, ellos entraron por acá, por la finca.

A nivel personal sí, no porque me hayan dado, sino porque he tenido personal hospedado y por el servicio de alimentación, eso ha hecho que yo pueda mejorar mi establecimiento y no solamente yo, otras señoras también, con eso hemos podido surgir. 


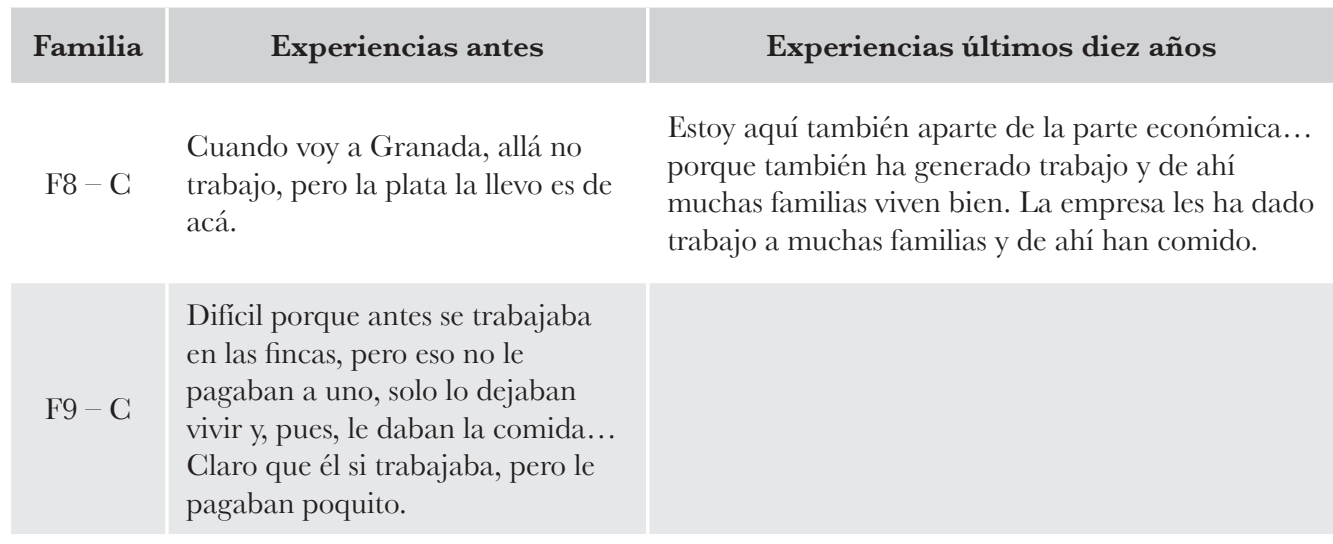

$\mathrm{F} 10-\mathrm{C}$

F11-F

F12 - F

F13 - F

F14-F
Sí, claro, ha mejorado, porque es diferente de una cocina a acá, que estoy tratando con una oficina... Ya llevo un año.

Pues, digamos sí, en sus tiempos, pero en el momento, actualmente, no.

Por acá el trabajo que hay es el de las empresas, no más.

Yo ya he mandado a trabajar a dos y ahorita tengo tres en producción.
F15 - F Antes nada, solo fincas.

F16-F

Era cuidando un hato, trabajando

F17 - F en una finca o sacando madera...

El trabajo tenía que ser muy mínimo.

\begin{tabular}{|l|l}
\hline $\mathrm{F} 15-\mathrm{F}$ & Antes nada, solo fincas. \\
\hline $\mathrm{F} 16-\mathrm{F}$ & $\begin{array}{l}\text { Era cuidando un hato, trabajando } \\
\text { en una finca o sacando madera... }\end{array}$ \\
$\mathrm{F} 17-\mathrm{F}$ & $\begin{array}{l}\text { El trabajo tenía que ser muy } \\
\text { mínimo. }\end{array}$ \\
\hline
\end{tabular}

F18-F

F19-F

F20 - F
Pero ahora sí, con la empresa, pues por eso nos vinimos, porque afuera la situación está dura y la paga mala. Aquí pagan bien, toca pesado, pero bueno.

Pues ha habido el empleo, pues no he estado directo con la empresa, pero sí indirecto.

Prácticamente sí en un momento, porque tenemos un beneficio, porque hay trabajo, hay personal circulando, hay consumo... Pero estas empresas la cantidad de empleo que han generado.

Vendo víveres, gaseosas a la comunidad, y usted sabe que también la empresa... que trabajadores, eso es en lo que nos beneficia, no más.

Mis clientes son personas de la comunidad, de la empresa, acojo a los vendedores y dentro de esos está el mulero... Un negocio muy rentable.

Fuente: Construcción propia a partir de los datos suministrados 
Representaciones sociales frente a la responsabilidad social de la industria petrolera y su influencia en la calidad...

Jennifer Sherelyn Sierra Arevalo

Esta condición es la más significativa para ellos, ya que anteriormente trabajaban en su mayoría como jornaleros y la remuneración era poca; ahora tienen mejores salarios y algo importante: la seguridad social.

"Trabajábamos como mensual en fincas... Si en la finca se enfermaba, del sueldo tenía que comprar la droga, en cambio con la empresa, se encarga de sacarlo y pagar, y eso es bueno".

(F1-AI, comunicación personal del 25 de febrero de 2013).

El tener una mejor condición económica les ha permitido mejorar sus condiciones habitacionales, brindar una mejor calidad de educción a sus hijos e incluso tener espacios de ocio y esparcimiento. De hecho, las ofertas laborales y salariales que ofrecen las empresas de hidrocarburos y sus contratistas son el principal motivo por el cual llega personal foráneo a la región y, por ende, a la vereda Rubiales.

\section{Matriz de análisis}

Categoría III. Calidad de vida

¿Cómo era el acceso a servicios de transporte antes de la llegada de las operadoras?

\begin{tabular}{|c|c|c|}
\hline Familia & Experiencias antes & Experiencias últimos diez años \\
\hline $\mathrm{F} 1-\mathrm{AI}$ & $\begin{array}{l}\text { Casi no salíamos, y el que salía era } \\
\text { porque tenía carro y era el traía y } \\
\text { llevaba las cosas y los mercados... Antes } \\
\text { era dificultoso salir porque así tuviera } \\
\text { ganas de salir tocaba aguantárselas. }\end{array}$ & \\
\hline $\mathrm{F} 2-\mathrm{AI}$ & & Me he beneficiado del transporte. \\
\hline $\mathrm{F} 3-\mathrm{AI}$ & $\begin{array}{l}\text { No había, tocaba salir a pie o en } \\
\text { bicicleta y de vez en cuando salía un } \\
\text { furgón. }\end{array}$ & \\
\hline $\mathrm{F} 4-\mathrm{C}$ & & $\begin{array}{l}\text { Una inversión, los buses, aunque no los he } \\
\text { podido utilizar porque siempre está el cupo. }\end{array}$ \\
\hline \multicolumn{3}{|l|}{$\mathrm{F} 5-\mathrm{C}$} \\
\hline $\mathrm{F} 6-\mathrm{C}$ & & $\begin{array}{l}\text { Pues eso sería como ser desagradecido de mi } \\
\text { parte porque que lo lleven y lo traigan a uno } \\
\text { gratis. Pues que briega uno un poquito a ratos, } \\
\text { pero para lo de la anotada a veces. }\end{array}$ \\
\hline
\end{tabular}




\begin{tabular}{|c|c|c|}
\hline Familia & Experiencias antes & Experiencias últimos diez años \\
\hline $\mathrm{F} 7-\mathrm{C}$ & $\begin{array}{l}\text { Solo había un carro de un propietario } \\
\text { que salía esporádicamente, de resto en } \\
\text { cicla, a pie o a caballo... Se llevaban } \\
\text { un poco de cotizas y se las iban } \\
\text { cambiando. }\end{array}$ & \\
\hline \multicolumn{3}{|l|}{$\mathrm{F} 8-\mathrm{C}$} \\
\hline $\mathrm{F} 9-\mathrm{C}$ & $\begin{array}{l}\text { Solo cicla o a pie, algunos tuvieron } \\
\text { moto, pero mucho después, en esa } \\
\text { época casi no se salía... Andábamos } \\
\text { incomunicados. }\end{array}$ & \\
\hline $\mathrm{F} 10-\mathrm{C}$ & & $\begin{array}{l}\text { Los cinco buses que se han presentado para las } \\
\text { comunidades y el otro, el de los estudiantes. }\end{array}$ \\
\hline $\mathrm{F} 11-\mathrm{F}$ & & $\begin{array}{l}\text { Lo de la ruta escolar también... Pues, la } \\
\text { verdad, desde que yo entré siempre ha habido } \\
\text { bus, antes estaba el de Marucha. }\end{array}$ \\
\hline $\mathrm{F} 12-\mathrm{F}$ & & $\begin{array}{l}\text { Los buses que hacen la ruta de Gaitán a } \\
\text { Rubiales... El bus de la escuela. }\end{array}$ \\
\hline $\mathrm{F} 13-\mathrm{F}$ & & $\begin{array}{l}\text { El bus, sea como sea, va despacito. pero lo } \\
\text { lleva a uno. }\end{array}$ \\
\hline $\mathrm{F} 14-\mathrm{F}$ & & Del bus es de lo que yo más me he beneficiado. \\
\hline $\mathrm{F} 15-\mathrm{F}$ & $\begin{array}{l}\text { Sé que andaban en cicla o a pie, por } \\
\text { aquí no sube bus de línea. }\end{array}$ & Ahora el que puso la empresa. \\
\hline $\mathrm{F} 16-\mathrm{F}$ & & $\begin{array}{l}\text { O sea, tenemos el servicio del bus hacia Gaitán } \\
\text { y los niños también... Ha sido bueno, yo } \\
\text { pienso que ha sido bueno. }\end{array}$ \\
\hline
\end{tabular}

He escuchado historias de gente que caminaba días para llegar a Gaitán,

F17 - F otros en cicla, otros en moto... Era pésimo, compraban el mercado para quince días o el mes... Cazaban.
Ahora hay medios de transporte, vías, hasta helicóptero hay.

Los buses del transporte.

Son diez cupos por vereda, pero a veces se presenta la necesidad de que uno debe salir y resulta que no porque hay familias que ocupan cuatro y hasta seis puestos.

Tuve la oportunidad varias veces de salir en avión y me facilitaban la camioneta. 
En cuanto a transporte, anteriormente no contaban con ningún servicio, los desplazamientos debían hacerlos a pie, en bicicleta y algunos a caballo. Por lo tanto, para las remesas, las familias hacían trueque, cambiaban mercado por cerdos. Y en temas de salud, el desplazamiento de una persona enferma era muy difícil. Ahora, con la existencia de buses que transportan a los habitantes de la vereda a diario, las posibilidades de acceder a los diferentes bienes y servicios que ofrece el casco urbano son mucho mayores, e incluso la conexión con las ciudades de Villavicencio, Bogotá y los diferentes lugares de su interés.

\section{Matriz de análisis}

Categoría III. Calidad de vida

¿Cómo era el acceso a recreación antes de la llegada de las operadoras?

\begin{tabular}{|c|c|c|}
\hline Familia & Experiencias antes & Experiencias últimos diez años \\
\hline $\mathrm{F} 1-\mathrm{AI}$ & $\begin{array}{l}\text { Nosotros hacíamos una pelotica de } \\
\text { trapo y con eso jugábamos. }\end{array}$ & $\begin{array}{l}\text { Gracias a Dios ahora tienen un balón y una } \\
\text { cancha para jugar. }\end{array}$ \\
\hline $\mathrm{F} 2-\mathrm{AI}$ & & $\begin{array}{l}\text { A los niños los llevaron por ahí a Villao... a un } \\
\text { paseo... a echar baño. }\end{array}$ \\
\hline $\mathrm{F} 3-\mathrm{AI}$ & $\begin{array}{l}\text { No, nada, pues uno jugaba por ahí } \\
\text { con palos y piedras, pero no había } \\
\text { nada... no había fiestas... }\end{array}$ & $\begin{array}{l}\text { No había fiestas ni regalos, como hace en la } \\
\text { escuela la empresa... Eso a los niños les gusta } \\
\text { mucho. }\end{array}$ \\
\hline \multicolumn{3}{|l|}{$\mathrm{F} 4-\mathrm{C}$} \\
\hline \multicolumn{3}{|l|}{$\mathrm{F} 5-\mathrm{C}$} \\
\hline \multicolumn{3}{|l|}{$\mathrm{F} 6-\mathrm{C}$} \\
\hline $\mathrm{F} 7-\mathrm{C}$ & & $\begin{array}{l}\text { Recreación cuando vienen las brigadas de } \\
\text { salud con el Ejército... La empresa también les } \\
\text { celebra el Día del Niño, la Navidad, diferentes } \\
\text { actividades... Una ludoteca también trajeron un } \\
\text { tiempo. }\end{array}$ \\
\hline $\mathrm{F} 8-\mathrm{C}$ & & $\begin{array}{l}\text { Hacia la parte de diciembre, enero... sancocho, } \\
\text { recreación con mi familia, al río, subimos, } \\
\text { bailamos, o sea, la pasamos, chévere. }\end{array}$ \\
\hline $\mathrm{F} 9-\mathrm{C}$ & $\begin{array}{l}\text { No, recreación no, pues los niños } \\
\text { jugaban en la casa, pero juguetes o } \\
\text { balones, no. }\end{array}$ & $\begin{array}{l}\text { Igual, ahora solo está el parque de la escuela, lo } \\
\text { único sí son las celebraciones del día de las brujas } \\
\text { y la Navidad, esas fiestas los niños las disfrutan } \\
\text { mucho... y uno también. }\end{array}$ \\
\hline $\mathrm{F} 10-\mathrm{C}$ & & \\
\hline
\end{tabular}




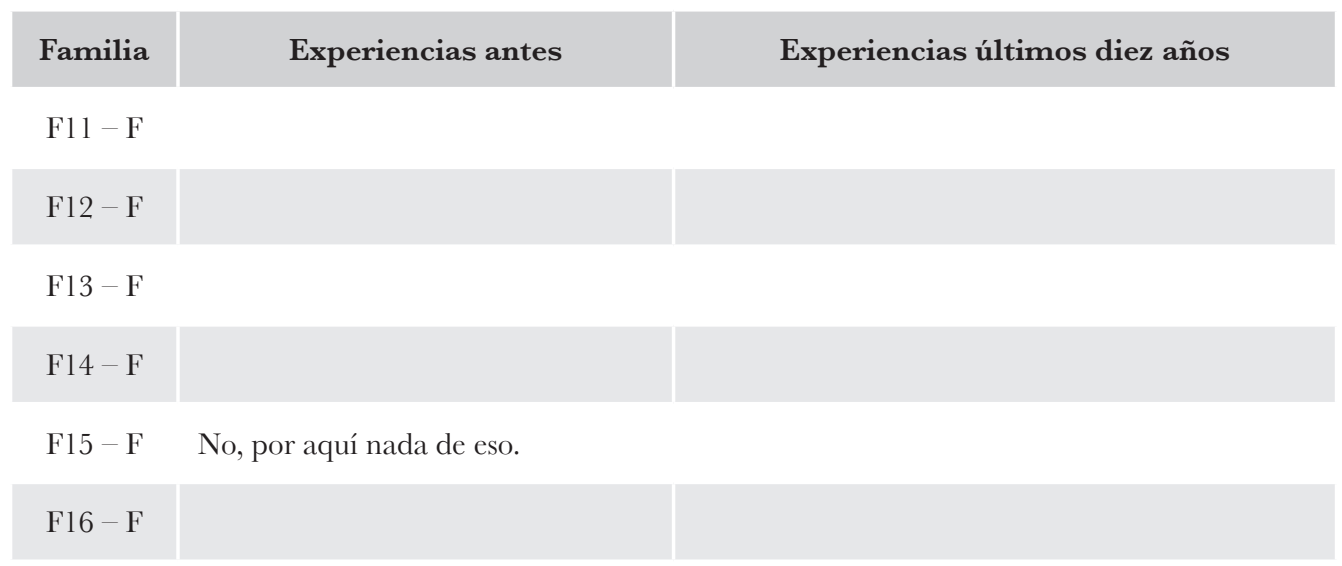

$$
\mathrm{F} 17-\mathrm{F}
$$

F18-F

F19-F

F20 - F
Recreación sí estamos como mal, porque por ahí viendo televisión o saliendo a bañarse a alguna laguna... Los niños se recrean es en la escuela, que tiene juegos lúdicos.
Las vacaciones recreativas fue un programa buenísimo, por lo menos a los niños les gustó... Otra cosa el Programa de Fortalecimiento de las Mujeres, que organizó dinámicas, recreación, también fue un espacio bueno.

Nos han ayudado en muchas cosas, como las salidas pedagógicas que tuvimos una vez, fue una experiencia muy bonita para los estudiantes y para los docentes.

Fuente: Construcción propia a partir de los datos suministrados

Anteriormente, la recreación se basaba en juegos con pelotas de trapo y lo que su imaginación en el contexto del campo les permitiera. Ahora las empresas han llevado sus tradiciones en cuanto a la celebración del Día de los Niños, la Navidad o llevarlos a Villavicencio o a Bogotá a parques de diversiones y salidas pedagógicas con la escuela; esto les ha gustado mucho tanto a los niños como a los padres. Los adultos también han visto el trabjo con las empresas como una oportunidad para acceder a la recreación.

"Hacia la parte de diciembre, enero... sancocho, recreación con mi familia, al río, subimos, bailamos, o sea, la pasamos chévere".

(F8-C, comunicación personal del 26 de febrero de 2013). 


\section{Matriz de análisis}

Categoría III. Calidad de vida

¿Considera que el nivel de vida de su hogar en los últimos años ha mejorado, empeorado o se mantiene igual? ¿Por qué?

\begin{tabular}{|c|c|c|c|}
\hline Familia & Ha mejorado & Esta igual & Empeoró \\
\hline $\mathrm{F} 1-\mathrm{AI}$ & En educación ha mejorado & & $\begin{array}{l}\text { En salud, por la } \\
\text { contaminación, los } \\
\text { niños mantienen } \\
\text { con diarrea. }\end{array}$ \\
\hline $\mathrm{F} 2-\mathrm{AI}$ & Sí, ha mejorado porque hay trabajo. & & $\begin{array}{l}\text { Lo que sí nos jode } \\
\text { es el polvero. }\end{array}$ \\
\hline $\mathrm{F} 3-\mathrm{AI}$ & $\begin{array}{l}\text { Sí, ha mejorado porque ahora vivimos en una } \\
\text { buena casa y, pues, miesposo trabaja en la em- } \\
\text { presa. }\end{array}$ & & \\
\hline $\mathrm{F} 4-\mathrm{C}$ & $\begin{array}{l}\text { No, mi familia en nivel ha mejorado el } 100 \% \ldots \\
\text { Gracias a Dios, como vuelvo y le digo a Pacific, } \\
\text { porque ellos me han brindado trabajo y he } \\
\text { trabajado y he sacado a mis hijos adelante. }\end{array}$ & & \\
\hline $\mathrm{F} 5-\mathrm{C}$ & & $\begin{array}{l}\text { Todo igual, } \\
\text { mire esta casa. }\end{array}$ & \\
\hline $\mathrm{F} 6-\mathrm{C}$ & $\begin{array}{l}\text { Que haya mejorado harto, inclusive en el caso } \\
\text { mío, porque cuando nosotros llegamos acá } \\
\text { teníamos escasamente el día y la noche, ya pues, } \\
\text { gracias a Dios, tenemos a dónde. No, y también } \\
\text { de mis hijos, mis hermanos, inclusive hasta de } \\
\text { mí mismo papá, porque él estuvo enfermo y con } \\
\text { lo que la empresa le colaboró, ya gracias a Dios } \\
\text { lo operaron de esa próstata y está bien, gracias a } \\
\text { Dios. }\end{array}$ & & \\
\hline
\end{tabular}

F7 - C Un $100 \%$ porque mi situación económica era pesada y ha mejoradomuchísimo en todo sentido.

Yo aquí vivo delicioso porque ya aquí tengo todo... Hacia la parte económica, bien, y mi hijo está estudiando... Gracias a Dios hemos tenido

F8 - C trabajo... Yo vivo muy bien acá... Yo mantengo muy feliz acá... En Granada tenemos luz, agua, todo, pero nos amañamos más acá porque acá esta la parte económica.

F9-C Sí, porque hay trabajo fijo, tenemos seguridad social y, pues, todas las ayudas que da la empresa. 


\begin{tabular}{|l|c|} 
Familia & \multicolumn{1}{c}{ Ha mejorado } \\
\hline F10-C & $\begin{array}{l}\text { No, harto, harto, ha influido totalmente porque } \\
\text { como anteriormente yo acabo de venir de lo } \\
\text { de las comidas... Ya ahorita llevo tres años } \\
\text { trabajando con la empresa, entonces, lógico que } \\
\text { me ha cambiado la vida... Sí, claro, ha mejorado } \\
\text { porque es diferente en una cocina a acá, que } \\
\text { estoy tratando con una oficina. }\end{array}$ \\
\hline
\end{tabular}

\begin{tabular}{|c|c|}
\hline F11-F & $\begin{array}{l}\text { No, pues yo pienso que gracias a que existe la } \\
\text { empresa es que hay tanta comunidad acá... } \\
\text { o sea, por trabajo, porque es que afuera la } \\
\text { situación, de verdad, está crítica. }\end{array}$ \\
\hline $\mathrm{F} 12-\mathrm{F}$ & $\begin{array}{l}\text { Claro, claro, porque obvio, porque si la empresa } \\
\text { no estuviera acá, no habría empleo. }\end{array}$ \\
\hline $\mathrm{F} 13-\mathrm{F}$ & $\begin{array}{l}\text { Yo le debo mucho, por ahorita me van a traer } \\
\text { un medio de transporte que no tenía cuando yo } \\
\text { llegué aquí, coloqué a un trabajador ahí... y me } \\
\text { van a recompensar con una moto. }\end{array}$ \\
\hline $\mathrm{F} 14-\mathrm{F}$ & $\begin{array}{l}\text { Yo siempre lo he dicho y lo diré... si no estuviera } \\
\text { la empresa, qué estaría viviendo por acá... } \\
\text { Para mí, ha mejorado. }\end{array}$ \\
\hline $\mathrm{F} 15-\mathrm{F}$ & $\begin{array}{l}\text { Ha mejorado, claro, desde que llegamos por aquí } \\
\text { bien, la platica no falta y tiene uno de todo, lo } \\
\text { difícil es el agua, que la sueltan dos horas por la } \\
\text { mañana y dos horas por la tarde, eso sí es lo feo. }\end{array}$ \\
\hline $\mathrm{F} 16-\mathrm{F}$ & $\begin{array}{l}\text { Pues en mi casa ha mejorado en cuanto, pues, a } \\
\text { que ha habido empleo, pues no he estado directo } \\
\text { con la empresa, pero sí indirecto, pues ahorita } \\
\text { que tenemos esa asociación. }\end{array}$ \\
\hline $\mathrm{F} 17-\mathrm{F}$ & $\begin{array}{l}\text { En términos generales, sí, porque uno viene a } \\
\text { Rubiales con problemas financieros grandes, y } \\
\text { primero estoy amañado porque es tranquilo, } \\
\text { sano, hay trabajo, para mí, sí, ha mejorado. }\end{array}$ \\
\hline $\mathrm{F} 18-\mathrm{F}$ & $\begin{array}{l}\text { Sí señora, ha influido porque ha mejorado... } \\
\text { Mi esposa, ella vive muy agradecida. }\end{array}$ \\
\hline $\mathrm{F} 19-\mathrm{F}$ & $\begin{array}{l}\text { Para mí sí ha sido un buen beneficio porque } \\
\text { por el negocio hay más ingresos, hay más } \\
\text { posibilidades económicas... Sí, mejora la calidad } \\
\text { de vida. }\end{array}$ \\
\hline
\end{tabular}

F20 - F

Fuente: Construcción propia a partir de los datos suministrados 
Representaciones sociales frente a la responsabilidad social de la industria petrolera y su influencia en la calidad...

Para las familias con ascendencia indígena y para los colonos, la presencia de estas empresas significó también la llegada de mejores opciones laborales, de educación, de salud, de transporte, las cuales antes no tenían. Y para quienes vienen de otras regiones es significativo poder acceder a una oferta laboral en la que el salario mínimo duplique el nacional, lo que les permite adquirir los satisfactores de sus necesidades y mejorar así su calidad de vida. Sin embargo, las afectaciones por el material particulado influyen también en su bienestar, considerando que se afecta su salud, principalmente la de los niños.

"Mi familia en nivel ha mejorado el 100 \%... Gracias a Dios, como vuelvo y le digo a Pacific, porque ellos me han brindado trabajo y he trabajado y he sacado a mis hijos adelante".

(F4-G, comunicación personal del 25 de febrero de 2013). 


\section{Conclusiones y recomendaciones}

La representación social que los habitantes de la vereda Rubiales construyen frente a la responsabilidad social de la industria petrolera y su influencia en su calidad de vida se presenta diferente en cada uno de los grupos poblacionales. Para la población con ascendencia indígena, ha sido buena en términos de acceso a salud, educación, transporte y mejoramiento de vivienda, pero es sentida su inconformidad con las afectaciones ambientales relacionadas con la generación de material particulado por la alta circulación de vehículos por las vías internas de la vereda, que, a pesar de tener carrotanques haciendo aspersión de agua e instalando asfalto espumado sobre las vías, esto no es suficiente; argumentan que esto ha influido en que sus niños presenten enfermedades respiratorias. Los colonos ven la responsabilidad social como un canal de comunicación entre los diferentes grupos de interés, por medio de la cual se canalizan y atienden sus necesidades y requerimientos. Reconocen como una oportunidad la presencia de la industria en la vereda, ya que con esta llegó el acceso a servicios de salud, educación, transporte, proyectos productivos, oportunidades laborales y la facilidad de adquirir bienes y servicios; sin embargo, también manifiestan que no se les ha cumplido con un proyecto de mejoramiento de vivienda que se les prometió hace varios años, y que las operadoras no han querido apoyar proyectos de energía y acueducto, los cuales representan sus principales necesidades; dicen tener claro que no es una responsabilidad suya, pero que sí pueden gestionar ante el Gobierno municipal y departamental una alianza estratégica que permita la consecución de estos proyectos. Los foráneos la ven como una figura que ayuda a resolver todo tipo de necesidades, la ven como una ventaja, pues tienen acceso a salud, educación y transporte gratis. Para este grupo es relevante el tema del empleo, pues es la principal razón que los ha movido a llegar a la vereda, y refieren que mejorar su economía es tener calidad de vida, pues así pueden satisfacer muchas de sus necesidades. Para estas familias es preocupante también la ausencia de servicios de energía y acueducto; sin embargo, sienten como un aliciente contar con la donación de una planta de energía por parte de la operadora, la cual podrá suplir estas necesidades.

Lo anterior sugiere a la operadora actual dar atención a la problemática de la contaminación ambiental (material particulado) a fin de dar una solución definitiva considerando que la responsabilidad social, además de contribuir con la sociedad mejorando la calidad de vida de las comunidades, es trabajar en armonía con el medio ambiente.

Finalmente, una tarea importante para el área de la Responsabilidad Social es trabajar con las comunidades, orientarlas en el diseño y la formulación de sus planes de acción a nivel local. Y para el Estado, conocer las problemáticas sociales y las necesidades que tienen las comunidades rurales es una oportunidad de trabajar en la formulación de políticas sociales que garanticen la atención de estas haciéndolas parte de la agenda política. 
Representaciones sociales frente a la responsabilidad social de la industria petrolera y su influencia en la calidad... Jennifer Sherelyn Sierra Arevalo

\section{Referencias}

Abela, J. (2002). Las técnicas de análisis de contenido: Una revisión actualizada. Andalucía: Fundación Centro de Estudios Andaluces. Recuperado de http://public.centrodeestudiosandaluces.es/pdfs/S200103.pdf

Bardin, L. (1999). Análisis de contenido: Una revisión actualizada. Madrid: Akal Ediciones.

Barroso, F. (2008). La responsabilidad social empresarial. Un estudio en cuarenta empresas de la ciudad de Mérida, Yucatán. México. Contaduría y Administración, 226, 7391. Recuperado de http://www.redalyc.org/articulo.oa?id=39522605

Ficher, G. N. (1990). Psicología social. Conceptos fundamentales. Madrid: Universidad de Metz.

Hall, L. (2008). La calidad de vida en vecindarios urbanos de Costa Rica (Documento de trabajo R-563). Nueva York: BID. Recuperado de goo.gl/ei0dzh

Icontec, (2009). Normalización de la responsabilidad social. Recuperado de http://www.slideshare.net/boyacaresponsable/icontec

Isaza, J. y Rendón, J. (2007). Guía metodológica para la formulación y presentación de proyectos de investigación. Bogotá: Universidad de La Salle.

Jodelet, D. (1985). La representación social: Tendencias, conceptos y teoría. En Psicología social II. Pensamiento y valor social. Barcelona: Paidos.

León, E., Barragán, D. y Ravelo, E. (2009). Las representaciones sociales del concepto de responsabilidad social en los estudiantes de contaduría pública: Hacia la estructura del sentido común. Revista Facultad de Ciencias Económicas: Investigación y Reflexión, 17(2), 61-97. Recuperado de http://www.redalyc.org/articulo.oa?id=90913042004

León Guillard, M. O. (2009). Factores que inciden en la calidad de vida del adulto mayor, en una muestra de la población del municipio de Marianao. Bioética, 9(2), 18-22. Recuperado de http://www.cbioetica.org/revista/92/921822.pdf

PNUD. (1990). Desarrollo Humano. Informe 1990. Recuperado de http://hdr.undp.org/ sites/default/files/hdr_1990_es_completo_nostats.pdf

PNUD. (2011). Informe Nacional de Desarrollo Humano 2011. Colombia rural. Razones para la esperanza. Recuperado de goo.gl/M3n5UM

Rodríguez, T. (2008). Sobre el potencial teórico de las representaciones sociales en el campo de la comunicación. Comunicación y Sociedad, 11, 11-36. Recuperado de http:/ / www.redalyc.org/articulo.oa?id=34611503002 
ISSN: 0124-3551 / Año 17, No 27 / julio-diciembre / pp. 103-148

Salcedo, F. (1994). Representaciones sociales y movimientos sociales II. Imaginarios representaciones e identidades masculinas sobre el aborto inducido. Trabajo presentado en el Encuentro de Investigadores sobre Aborto Inducido en América Latina y el Caribe. Universidad Externado de Colombia, Bogotá.

Sandoval, G. (1997). Investigación cualitativa (módulo 4). Bogotá: ICFES.

Vergara, R., Alonso, L., Palacio, J. y Rojas, M. (2009). El desarrollo humano y la calidad de vida integrados en un modelo de gestión urbana para Barranquilla (Colombia). Revista Salud Uninorte, 25(2), 374-390. Recuperado de http://www.redalyc.org/articulo.oa?id=81712365015

Vasilachis, I. (2006). La investigación cualitativa. En I. Vasilachis (coord.), Estrategias de investigación cualitativa (pp. 23-64). Barcelona: Editorial Gedisa. Recuperado de goo. gl/by3Gp6 